\title{
Retrieval of nitrogen dioxide stratospheric profiles from ground-based zenith-sky UV-visible observations: validation of the technique through correlative comparisons
}

\author{
F. Hendrick ${ }^{1}$, B. Barret ${ }^{1, *}$, M. Van Roozendael ${ }^{1}$, H. Boesch ${ }^{2, * *}$, A. Butz ${ }^{2}$, M. De Mazière ${ }^{1}$, F. Goutail ${ }^{3}$, C. Hermans ${ }^{1}$, \\ J.-C. Lambert ${ }^{1}$, K. Pfeilsticker ${ }^{2}$, and J.-P. Pommereau ${ }^{3}$ \\ ${ }^{1}$ Institut d'Aéronomie Spatiale de Belgique (IASB-BIRA), Brussels, Belgium \\ ${ }^{2}$ Institute for Environmental Physics, University of Heidelberg, Germany \\ ${ }^{3}$ Service d'Aéronomie du CNRS, Verrieres le Buisson, France \\ *now at: Service de Chimie Quantique et Photophysique: atomes, molécules et atmosphères, Université Libre de Bruxelles, \\ Belgium \\ *** now at: Jet Propulsion Laboratory, Pasadena, California, USA
}

Received: 8 April 2004 - Published in Atmos. Chem. Phys. Discuss.: 25 May 2004

Revised: 14 September 2004 - Accepted: 18 September 2004 - Published: 21 October 2004

\begin{abstract}
A retrieval algorithm based on the Optimal Estimation Method (OEM) has been developed in order to provide vertical distributions of $\mathrm{NO}_{2}$ in the stratosphere from ground-based (GB) zenith-sky UV-visible observations. It has been applied to observational data sets from the NDSC (Network for Detection of Stratospheric Change) stations of Harestua $\left(60^{\circ} \mathrm{N}, 10^{\circ} \mathrm{E}\right)$ and Andøya $\left(69^{\circ} \mathrm{N}, 16^{\circ} \mathrm{E}\right)$ in Norway. The information content and retrieval errors have been analyzed following a formalism used for characterizing ozone profiles retrieved from solar infrared absorption spectra. In order to validate the technique, the retrieved $\mathrm{NO}_{2}$ vertical profiles and columns have been compared to correlative balloon and satellite observations. Such extensive validation of the profile and column retrievals was not reported in previously published work on the profiling from GB UV-visible measurements. A good agreement - generally better than $25 \%$ - has been found with the SAOZ (Système d'Analyse par Observations Zénithales) and DOAS (Differential Optical Absorption Spectroscopy) balloons. A similar agreement has been reached with correlative satellite data from the HALogen Occultation Experiment (HALOE) and Polar Ozone and Aerosol Measurement (POAM) III instruments above $25 \mathrm{~km}$ of altitude. Below $25 \mathrm{~km}$, a systematic underestimation - by up to $40 \%$ in some cases - of both HALOE and POAM III profiles by our GB profile retrievals has been observed, pointing out more likely a limitation of both satellite instruments at these altitudes. We have concluded that our study strengthens our confidence in the reliability of the
\end{abstract}

Correspondence to: $\mathrm{F}$. Hendrick

(franch@oma.be) retrieval of vertical distribution information from GB UVvisible observations and offers new perspectives in the use of GB UV-visible network data for validation purposes.

\section{Introduction}

The vertical distribution of stratospheric nitrogen dioxide $\left(\mathrm{NO}_{2}\right)$ can be retrieved from ground-based (GB) measurements of the absorption of zenith-scattered sunlight. Basically, at visible wavelengths where $\mathrm{NO}_{2}$ absorption is measured, the mean altitude at which Rayleigh scattering occurs increases with increasing solar zenith angle (SZA). During twilight, the mean scattering altitude scans the stratosphere rapidly, yielding height-resolved information on the absorption by stratospheric $\mathrm{NO}_{2}$. Since the pioneering works of Brewer et al. (1973) and Noxon (1975), only a few attempts (McKenzie et al., 1991; Preston et al., 1997; Denis et al., submitted, 2003 ${ }^{1}$; Schofield et al., 2004) have been reported on the retrieval of vertical distributions of atmospheric trace gases from GB zenith-sky observations. The most comprehensive studies are those of Preston et al. (1997), Denis et al. (submitted, 2003 ${ }^{1}$ ), and Schofield et al. (2004). They have all benefited from the theoretical developments in the inversion techniques due to Rodgers $(1976,1990,2000)$, especially those concerning the characterization of the retrieval.

\footnotetext{
${ }^{1}$ Denis, L., Roscoe, H. K., Chipperfield, M. P., Van Roozendael, M., and Goutail, F.: A new software for $\mathrm{NO}_{2}$ vertical profile retrieval from ground-based zenith-sky spectrometers, submitted to JQSRT, 2003.
} 
Preston et al. (1997) retrieved the $\mathrm{NO}_{2}$ vertical distribution in the stratosphere from zenith-sky observations using the Optimal Estimation Method (OEM) (Rodgers, 1976, 1990, 2000). A similar study has been carried out by Denis et al. (submitted, 2003 ${ }^{1}$ ) but their focus was on the optimization of an inversion software package for operational and routine retrievals. In Schofield et al. (2004), the retrieval algorithm was also based on the OEM but it has been applied to combined GB zenith-sky and direct-sun measurements of bromine monoxide $(\mathrm{BrO})$. Due to scattering geometry considerations, zenith-sky and direct-sun observations are sensitive to the stratosphere and the troposphere, respectively. Therefore, combining both viewing geometries in a formal retrieval provides information on both stratospheric and tropospheric absorbers. All the three studies stressed the impact of the photochemistry on the retrieved information. Trace gas species like $\mathrm{NO}_{2}$ and $\mathrm{BrO}$ display a strong diurnal variation which complicates the retrieval: the observed variation of the measurements with SZA depends not only on the scattering geometry (as aforementioned, the mean scattering altitude increases with increasing SZA) but also on the photochemistry (the concentration of $\mathrm{NO}_{2}$ and $\mathrm{BrO}$ increases and decreases with SZA, respectively). The photochemical effect was supplied as a priori information in Preston et al. (1997) and Denis et al. (submitted, 2003 ${ }^{1}$ ) while it was simultaneously retrieved with the altitude distribution of the trace gas in Schofield et al. (2004).

Here we report on the retrieval using the OEM of $\mathrm{NO}_{2}$ stratospheric profiles from GB zenith-sky UV-visible observations performed at the NDSC (Network for the Detection of Stratospheric Change) stations of Harestua $\left(60^{\circ} \mathrm{N}, 10^{\circ} \mathrm{E}\right)$ and Andøya $\left(69^{\circ} \mathrm{N}, 16^{\circ} \mathrm{E}\right)$ in Norway. The paper is divided into four parts. In the first part, we describe the GB zenith-sky UV-visible observations on which the retrieval algorithm has been applied. The second and third parts of the paper are dedicated to the description of the inversion method and to the characterization of the retrievals, respectively. The information content and error analyses are presented in the formalism used by Barret et al. (2002) for characterizing the retrieval of ozone profiles from solar infrared absorption spectra and not applied until now to GB UV-visible data. Finally, in the fourth part, our retrieval algorithm is tested through comparisons of retrieved profiles and columns with correlative data. These are measurements from the balloon-borne Système d'Analyse par Observations Zénithales (SAOZ) and Differential Optical Absorption Spectroscopy (DOAS) instruments and the Polar Ozone and Aerosol Measurement (POAM) III and HALogen Occultation Experiment (HALOE) satellite instruments. Such a correlative comparison exercise provides a thorough validation of the retrievals, which is an advancement over previously published studies.

\section{Ground-based UV-visible observations}

In the present study, $\mathrm{NO}_{2}$ stratospheric profiles are retrieved using essentially the GB UV-visible zenith-sky observations continuously performed since 1998 at the NDSC station of Harestua. A few retrieval results obtained from measurements performed in March 2003 at Andøya during the NDSC intercomparison campaign of GB zenith-sky instruments (Vandaele et al., 2004²) are also presented. A description of the Harestua instrument can be found in Van Roozendael et al. (1998), the Andøya instrument being of similar design. GB measurements of zenith radiance spectra have been analyzed by the DOAS technique (e.g. Noxon, 1975; Platt, 1994) using a coupled linear/non-linear least-squares fitting algorithm. $\mathrm{NO}_{2}$ differential slant column densities (DSCDs) with respect to a reference amount - which are the direct product of the DOAS analysis - have been retrieved in the 410-440 nm (Harestua) and 425-450 nm (Andøya) wavelength regions, taking into account the spectral signatures of $\mathrm{O}_{3}, \mathrm{NO}_{2}, \mathrm{O}_{4}, \mathrm{H}_{2} \mathrm{O}$, and Ring effect. DSCDs measured at sunrise or sunset in the 75-94 $\mathrm{SZA}$ range are directly used as input by the retrieval algorithm, the amount of $\mathrm{NO}_{2}$ in the reference spectrum being fitted by the algorithm. The addition of the extra parameter of reference amount into the retrieval is identical to the determination of the reference amount prior to the retrieval using a method such as chemically modified Langley plots (Lee et al., 1994).

\section{Description of the method}

\subsection{Retrieval algorithm and parameters}

The problem of inverting vertical distributions of trace gas species from GB UV-visible observations has been extensively discussed in Preston et al. (1997) and Schofield et al. (2004). It consists of expressing the $\mathrm{NO}_{2}$ vertical profile at a given SZA (state vector $\boldsymbol{x}$ ) in terms of a set of DSCDs measured as a function of the SZA (measurement vector $\boldsymbol{y}$ ), the measurements being related to the vertical profile by a forward model $F$ describing the physics of the measurement process. As in the previously published studies (see Sect. 1), our retrieval algorithm is based on the OEM (Rodgers, 1976, 2000). In this method, a profile $\widehat{\boldsymbol{x}}$ is retrieved given an a priori profile $\boldsymbol{x}_{\boldsymbol{a}}$, the measurements $\boldsymbol{y}$, their respective uncertainty covariance matrices ( $\mathbf{S}_{\mathrm{a}}$ and $\mathbf{S}_{\varepsilon}$, respectively), and the matrix $\mathbf{K}$ of the weighting functions that indicate the sensitivity of the differential slant column abundances at each SZA to a change in the vertical profile:

$$
\widehat{\boldsymbol{x}}=\boldsymbol{x}_{\boldsymbol{a}}+\left(\mathbf{K}^{T} \mathbf{S}_{\varepsilon}^{-1} \mathbf{K}+\mathbf{S}_{a}^{-1}\right)^{-1} \mathbf{K}^{T} \mathbf{S}_{\varepsilon}^{-1}\left(\boldsymbol{y}-\mathbf{K} \boldsymbol{x}_{\boldsymbol{a}}\right)
$$

\footnotetext{
${ }^{2}$ Vandaele, A. C., Fayt, C., Hendrick, F., et al.: An intercomparison campaign of ground-based UV-Visible measurements of $\mathrm{NO}_{2}$, $\mathrm{BrO}$, and $\mathrm{OClO}$ slant columns, I. $\mathrm{NO}_{2}$, in preparation, 2004.
} 
with $\mathbf{K}=\frac{\partial \boldsymbol{y}}{\partial \boldsymbol{x}}$ and $\mathbf{K}^{T}$ is the transpose of $\mathbf{K}$.

The weighting functions have been determined by consecutively perturbing each layer of the a priori profile and recalculating the set of measurements using the forward model. The OEM for linear case is considered here because the measurements of optically thin absorbers like $\mathrm{NO}_{2}$ depend linearly on the concentrations in each layer. Therefore, the weighting function matrix $\mathbf{K}$ is independent of the state (Heskes and Boersma, 2003) and a single inversion step is sufficient. This is in contrast with optically thick constituents such as ozone whose weighting functions depend on small variations in the profile. In that case, an iterative inversion method is necessary with the weighting functions being recalculated with each iteration.

The a priori profile $\boldsymbol{x}_{\boldsymbol{a}}$ and the covariance matrices of uncertainties in the a priori profile and in the measurements $\left(\mathbf{S}_{\mathrm{a}}\right.$ and $\mathbf{S}_{\varepsilon}$, respectively) are key parameters for the retrieval. Because the retrieval problem is ill-conditioned (the error on some measurement components of the vector $\boldsymbol{y}$ can be large enough that these components become useless, resulting in the lack of a unique solution to Eq. 1), a priori constraints are necessary to reject unrealistic solutions that might be consistent with the measurements. The $\mathrm{NO}_{2}$ a priori profiles used in the present study are defined as concentration $\left(\right.$ molecule $/ \mathrm{cm}^{3}$ ) and are taken from the output of a stacked box photochemical model (see its description in Sect. 3.2) initialised at the location and day of the year of the GB UV-visible observations with the corresponding output for the year 1999 of the 3-D CTM SLIMCAT (Chipperfield, 1999). Photochemical model calculations give profile data from $\sim 10$ to $\sim 55 \mathrm{~km}$. Below the lowest altitude level of the photochemical model, the following expression is applied to calculate profile values: $\boldsymbol{x}_{\boldsymbol{a}}$ (level i) $=0.5 \boldsymbol{x}_{\boldsymbol{a}}($ level $\mathrm{i}+1)$. Thus, the $\mathrm{NO}_{2}$ tropospheric content in the a priori profile is made negligible for all the retrievals. Above the highest altitude level of the photochemical model, the US76 standard atmosphere completes the profile.

Since the residuals from the DOAS fitting were found to be in most cases dominated by the random noise of the detector, the measurement covariance matrix $\mathbf{S}_{\varepsilon}$ has been chosen diagonal with values corresponding to the statistical errors on the $\mathrm{NO}_{2}$ DOAS fitting. The $\mathbf{S}_{\varepsilon}$ matrix being fixed, the a priori covariance matrix $\mathbf{S}_{\mathrm{a}}$ can act like a tuning parameter (Schofield et al., 2004). The variance value to be placed on the diagonal of the $\mathbf{S}_{\mathrm{a}}$ matrix has been empirically determined and $10 \%$ was found to be the threshold value above which undesired oscillations in the retrieved profiles can occur. $\mathbf{S}_{\mathrm{a}}$ also contains extra-diagonal terms in order to account for correlations between $\mathrm{NO}_{2}$ values at different altitude levels. These terms were added as Gaussian functions as follows (Barret et al., 2002):

$$
\mathbf{S}_{\mathrm{aij}}=\sqrt{\mathbf{S}_{\mathrm{aii}} \mathbf{S}_{\mathrm{ajj}} \exp \left(-\ln (2)\left(\left(\mathrm{z}_{\mathrm{i}}-\mathrm{z}_{\mathrm{j}}\right) / \gamma\right)^{2}\right)} .
$$

where $z_{i}$ and $z_{j}$ are the altitudes of $i^{\text {th }}$ and $j^{\text {th }}$ levels, respectively and $\gamma$ is the half width at half maximum (HWHM). The choice of a correlation length of $8 \mathrm{~km}(\gamma=4 \mathrm{~km})$ is discussed in Sect. 4.2.

Concerning the characterization of the retrieval, the averaging kernels matrix A plays the most important role. The averaging kernels - which are the rows of the A matrix - express the relationship between the retrieved profile $\widehat{x}$ and the true atmospheric profile $x$ :

$\widehat{\boldsymbol{x}}=\boldsymbol{x}_{\boldsymbol{a}}+\mathbf{A}\left(\boldsymbol{x}-\boldsymbol{x}_{\boldsymbol{a}}\right)+$ Error terms.

The A matrix is derived using the following expression (Rodgers, 1990, 2000):

$\mathbf{A}=\frac{\partial \widehat{\boldsymbol{x}}}{\partial \boldsymbol{x}}=\left(\mathbf{K}^{\mathrm{T}} \mathbf{S}_{\varepsilon}^{-1} \mathbf{K}+\mathbf{S}_{\mathrm{a}}^{-1}\right)^{-1} \mathbf{K}^{\mathrm{T}} \mathbf{S}_{\varepsilon}^{-1} \mathbf{K}$.

Following Eq. (3), the retrieval of any profile point is an average of the entire true profile weighted by the row of the A matrix corresponding to the altitude of the retrieved profile point. For an ideal inverse method, the A matrix would be therefore equal to the identity matrix. In reality, rows of $\mathbf{A}$ are peaked functions since the retrieved profile is only a smoothed perception of the true profile. The vertical resolution of this smoothed information at a given altitude can be estimated by taking the full width at half maximum (FWHM) of the main peak of the corresponding averaging kernel. Another important characterization parameter which can be derived from the A matrix is the number of "degrees of freedom for signal" providing an estimate of the number of independent pieces of information that can be retrieved from the measurements. This parameter is given by the trace of $\mathbf{A}$ (Rodgers, 2000).

\subsection{The forward model}

As mentioned in Sect. 3.1, the forward model describes the physics of the measurement process. It consists of the stacked box photochemical model PSCBOX (Errera and Fonteyn, 2000; Hendrick et al., 2000) coupled to the radiative transfer (RT) package UVspec/DISORT (Kylling and Mayer, 2003). A photochemical model is required to reproduce the effect of the rapid variation of $\mathrm{NO}_{2}$ concentrations at twilight. It also provides a priori $\mathrm{NO}_{2}$ profiles for the retrieval (see Sect. 3.1). The RT model is used to calculate slant column abundances from the $\mathrm{NO}_{2}$ concentrations predicted by the photochemical model.

The PSCBOX model includes 48 variable species, 141 gas-phase photochemical reactions as well as heterogeneous reactions on liquid sulfuric acid aerosols and on solid nitric acid trihydrate (NAT) and ice particles. It is initialised daily at 17 independent altitude levels (between $\sim 10$ and $\sim 55 \mathrm{~km}$ of altitude) with 12:00 UT pressure, temperature, and chemical species profiles from the 3-D CTM SLIMCAT (Chipperfield, 1999). The chemical timestep is $6 \mathrm{~min}$; no family and 


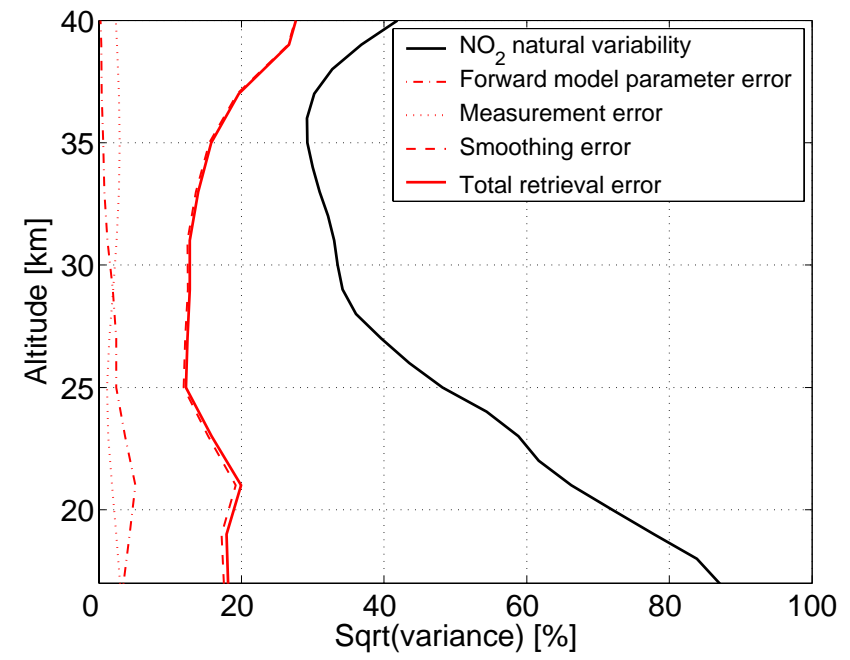

Fig. 1. Example profiles of the smoothing, measurement, forward model parameter, and total retrieval errors and profile of the $\mathrm{NO}_{2}$ natural variability. The retrieval errors are calculated for Harestua 25 May 2001 at sunset.

photochemical equilibrium assumptions are made. Updated kinetic and photochemical data are taken from the JPL 2000 compilation (Sander et al., 2000). Photolysis rates are computed off-line by using the radiative transfer module of the two-dimensional model SOCRATES (Huang et al., 1998).

The UVspec/DISORT RT model uses the discrete ordinate method in a pseudo-spherical geometry approximation in order to solve the RT equation. All the calculations are performed in multiple scattering mode and include Rayleigh scattering, Mie scattering (background conditions), and molecular absorptions. The ground albedo has been fixed to $25 \%$, and the wavelengths used were $418 \mathrm{~nm}$ (Harestua) and $438 \mathrm{~nm}$ (Andøya). The variation of the concentration of the absorbing species along the light path has been taken into account since it has a large impact on the calculation of the slant column densities of rapidly photolysing species such as $\mathrm{NO}_{2}$ or $\mathrm{BrO}$ (Sinnhuber et al., 2002). Both RT and photochemical models have been validated through intercomparison exercises (Hendrick et al., 2000, 2003).

\section{Characterization of the retrieval}

\subsection{Error budget}

The total error of the retrieved profile is the sum of three errors (Rodgers, 2000): the error due to the smoothing of the true profile or smoothing error, the error due to the measurement noise, and the error due to systematic errors in the forward model.

The smoothing error covariance matrix $\mathbf{S}_{\mathrm{s}}$ can be calculated using the following expression (Rodgers, 2000):

$\mathbf{S}_{\mathrm{s}}=(\mathbf{A}-\mathbf{I}) \mathbf{S}_{\mathrm{x}}(\mathbf{A}-\mathbf{I})^{\mathrm{T}}$,

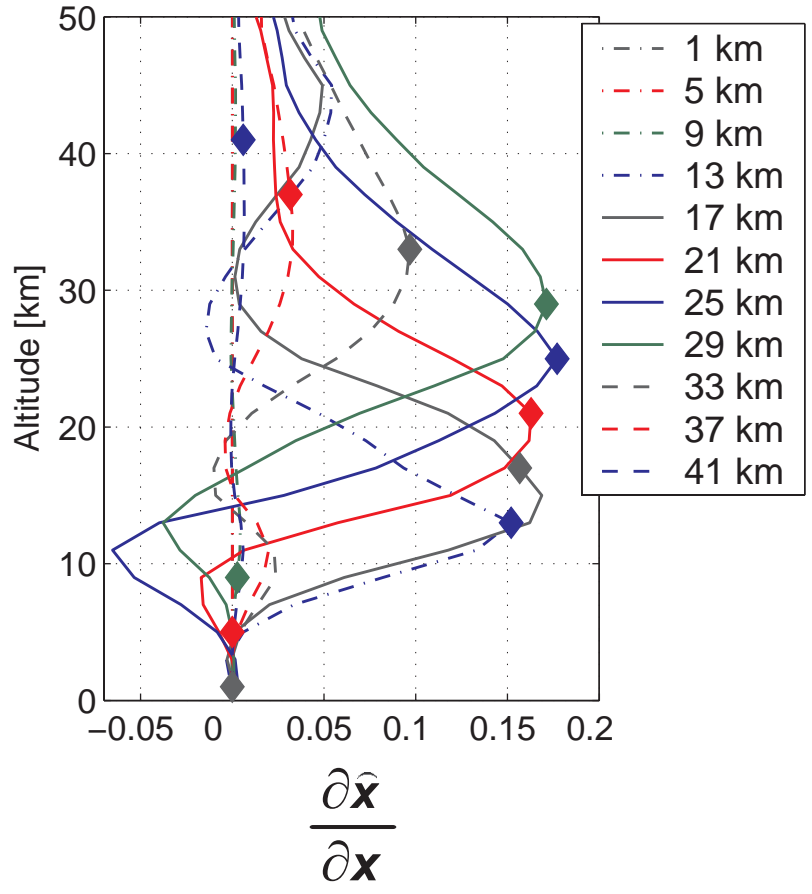

Fig. 2. Typical example of ground-based $\mathrm{NO}_{2}$ averaging kernels. They are calculated for the sunset Harestua 25 May 2001 retrieval. Plain diamonds indicate the altitude at which each averaging kernel should peak in an ideal case.

where $\mathbf{S}_{\mathrm{x}}$ is a realistic covariance matrix of the true $\mathrm{NO}_{2}$ profile, $\mathbf{A}$ is the averaging kernels matrix and $\mathbf{I}$ is the identity matrix. For the retrievals at Harestua, the variance of the true $\mathrm{NO}_{2}$ profile placed on the diagonal of the $\mathbf{S}_{\mathrm{x}}$ matrix has been estimated from the HALOE $\mathrm{NO}_{2}$ stratospheric profiles located in the $55^{\circ} \mathrm{N}-65^{\circ} \mathrm{N}$ latitude band over a period of five years (1998-2002). 1368 profiles were selected using these criteria, 437 at sunrise and 931 at sunset. They extend from end of February to mid-October, so that the seasonal variation of $\mathrm{NO}_{2}$ is largely taken into account. The use of the HALOE data for the present purpose has been limited to the $17-50 \mathrm{~km}$ altitude range (see Sect. 5.4 for a description of the HALOE $\mathrm{NO}_{2}$ observations). Due to the lack of large amounts of $\mathrm{NO}_{2}$ observational data to make reasonable statistics below $17 \mathrm{~km}$ and above $50 \mathrm{~km}$, the variance values calculated at 17 and $50 \mathrm{~km}$ from HALOE data have been extended to all the levels below $17 \mathrm{~km}$ and above $50 \mathrm{~km}$, respectively. $\mathbf{S}_{\mathrm{x}}$ also contains extra-diagonal terms in order to account for correlations between $\mathrm{NO}_{2}$ values at different altitude levels. These terms were added as Gaussian functions using the same expression and correlation length as for the $\mathbf{S}_{\mathrm{a}}$ matrix (see Eq. 2 in Sect. 3.1). Due to its latitude coverage, HALOE reaches the latitude region of Andøya only for a limited number of days during the year. Therefore, the $\mathbf{S}_{\mathrm{x}}$ matrix corresponding to this station cannot be constructed following a similar procedure as for Harestua (selection of 
HALOE profiles in the $65^{\circ} \mathrm{N}-75^{\circ} \mathrm{N}$ ). The most reasonable solution we found in this case has been to use, in a first approximation, the $\mathbf{S}_{\mathrm{x}}$ matrix constructed for Harestua.

The contribution of the measurement noise to the total retrieval error, also called the measurement error, is defined as (Rodgers, 2000):

$\mathbf{S}_{m}=\mathbf{G S}_{\varepsilon} \mathbf{G}^{T}$

with

$$
\mathbf{G}=\frac{\partial \widehat{\boldsymbol{x}}}{\partial \boldsymbol{y}}=\left(\mathbf{K}^{T} \mathbf{S}_{\varepsilon}^{-1} \mathbf{K}+\mathbf{S}_{a}^{-1}\right)^{-1} \mathbf{K}^{T} \mathbf{S}_{\varepsilon}^{-1},
$$

where $\mathbf{S}_{\varepsilon}$ is the covariance matrix of the noise in the measurements, and $\mathbf{G}$ is the contribution functions matrix expressing the sensitivity of the retrieved profile to changes in the measured $\mathrm{NO}_{2}$ slant column abundances. As mentioned in Sect. 3.1, the $\mathbf{S}_{\varepsilon}$ matrix was chosen diagonal with values corresponding to the statistical errors from the $\mathrm{NO}_{2}$ DOAS fitting.

The forward model parameter error $\mathbf{S}_{\mathrm{f}}$ is the retrieval error due to errors in the forward model parameters (e.g., errors on the rate constants in the photochemical model). $\mathbf{S}_{\mathrm{f}}$ is given by the following expression (Rodgers, 2000):

$\mathbf{S}_{\mathrm{f}}=\mathbf{G} \mathbf{K}_{\mathrm{b}} \mathbf{S}_{\mathrm{b}} \mathbf{K}_{\mathrm{b}}^{\mathrm{T}} \mathbf{G}^{\mathrm{T}}$,

where $\mathbf{G}$ is the contribution functions matrix (see Eq. 7), $\mathbf{K}_{\mathrm{b}}$ is the sensitivity of the forward model to perturbations of forward model parameters $\boldsymbol{b}$, and $\mathbf{S}_{\mathrm{b}}$ is the covariance matrix of $\boldsymbol{b}$. $\mathbf{S}_{\mathrm{f}}$ cannot be determined easily due to the large number of forward model parameters. In the present study, we have used the $\mathbf{S}_{\mathrm{f}}$ matrix derived by Preston et al. (1997) by calculating the sensitivity of the slant column measurements to large impact forward model (photochemical and/or RT models) parameters like $\mathrm{O}_{3}, \mathrm{HNO}_{3}, \mathrm{~N}_{2} \mathrm{O}_{5}$, aerosol, temperature profiles and ground albedo.

The profiles of the smoothing, measurement, and forward model parameter errors (square roots of the variances) corresponding to the sunset Harestua 25 May 2001 retrieval as well as the $\mathrm{NO}_{2}$ natural variability (square roots of the variances of $\mathbf{S}_{\mathrm{x}}$ ) are shown in Fig. 1. The main contribution to the total retrieval error is clearly due to the smoothing error, both measurement and forward model errors being only minor error sources. The total error is also significantly smaller than the $\mathrm{NO}_{2}$ natural variability over the $17-37 \mathrm{~km}$ altitude range, which means that variations of the $\mathrm{NO}_{2}$ profile smaller than the variations due to the natural variability can be detected from our GB UV-visible observations.

\subsection{Information content analysis}

As mentioned in Sect. 3.1, the averaging kernel matrix $\mathbf{A}$ is the key parameter for the characterization of the retrievals. Typical $\mathrm{NO}_{2}$ GB UV-visible averaging kernels are shown in Fig. 2. The averaging kernels between $13 \mathrm{~km}$ and $33 \mathrm{~km}$ are

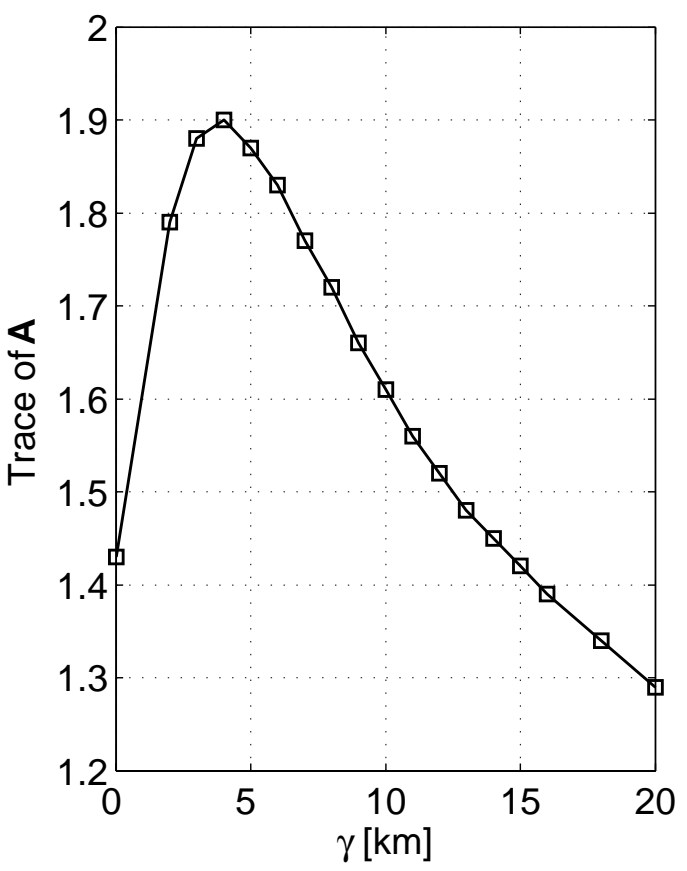

Fig. 3. Trace of the averaging kernels matrix A plotted as a function of the HWHM $(\gamma)$. This curve has been calculated for the sunset Harestua 25 May 2001 retrieval.

reasonably sharply peaked at their nominal altitude. From the examination of the averaging kernels for several dozens of sunsets and sunrises, it has been found that $13-37 \mathrm{~km}$ is the altitude range where the measurements give significant information about the vertical distribution of $\mathrm{NO}_{2}$. From Fig. 2, we also see that the vertical resolution is about $8 \mathrm{~km}$ at $13 \mathrm{~km}$ of altitude and reaches $20 \mathrm{~km}$ at an altitude of $33 \mathrm{~km}$. Typical values for the trace of $\mathbf{A}$ are close to 2, so there are about 2 independent pieces of information in the measurements. The $\mathbf{A}$ matrix depends on the a priori covariance matrix $\mathbf{S}_{\mathrm{a}}$ (see Eq. 3), and therefore on the correlation length between altitude levels used for the calculation of the extra-diagonal terms of $\mathbf{S}_{\mathrm{a}}$. The impact of this correlation length on the trace of $\mathbf{A}$ is large as it can be seen in Fig. 3 where the trace of $\mathbf{A}$ is plotted as a function of the $\gamma$ parameter which is the half of the correlation length (see Eq. 2). The trace of $\mathbf{A}$ is maximun (1.9) for a correlation length of $8 \mathrm{~km}(\gamma=4 \mathrm{~km})$ and the averaging kernels calculated with it are those shown in Fig. 2. Since such a feature has been obtained for a dozen of retrievals performed at sunrise and sunset and corresponding to different seasonal conditions (early winter, spring, summer, and early fall), a correlation length of $8 \mathrm{~km}$ has been used in all our retrievals. The number of independent pieces of information also depends on the SZA sampling (SZA upper limit and intervals) of the measurements. To illustrate that, calculations of the trace of $\mathbf{A}$ have been performed using different SZA upper limit values and three fixed SZA intervals $\left(1^{\circ}, 0.5^{\circ}\right.$, and $\left.0.25^{\circ}\right)$ in addition to the original SZA intervals 


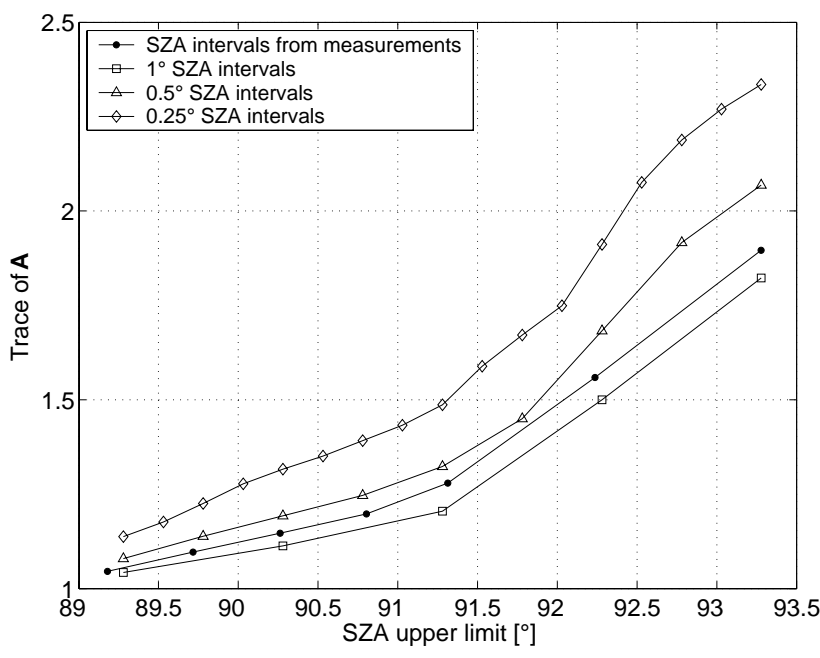

Fig. 4. Impact of the SZA sampling (SZA upper limit and SZA intervals) of the measurements on the number of independent pieces of information (trace of the averaging kernels matrix A). Synthetic measurements with fixed SZA intervals have been generated by using a polynomial fit through the sunset Harestua 25 May 2001 measurements and interpolating on the desired SZA grid.

of the measurements. Synthetic measurements with fixed SZA intervals have been generated by using a polynomial fit through the sunset Harestua May 25, 2001 measurements and interpolating on the desired SZA grid. The results of the calculations appear in Fig. 4 where the trace of $\mathbf{A}$ is plotted as a function of the SZA upper limit for the four SZA intervals. Fig. 4 shows that the trace of $\mathbf{A}$ increases with a decrease of the SZA intervals: e.g., when the SZA upper limit is $93.28^{\circ}$, the values of the trace of $\mathbf{A}$ for intervals of $1^{\circ}, 0.5^{\circ}$, and $0.25^{\circ}$ SZA are 1.82, 2.07, and 2.36, respectively, that means an increase of $30 \%$ from $1^{\circ}$ to $0.25^{\circ} \mathrm{SZA}$. As expected, the trace of $\mathbf{A}$ also increases with an increase of the SZA upper limit. 91.5 $\mathrm{SZA}$ seems to be a threshold value above which the increase of the trace of $\mathbf{A}$ with the SZA upper limit becomes faster (the slope below $91.5^{\circ} \mathrm{SZA}$ is smaller than the slope above this SZA value). These results should be taken into account when new DOAS instruments are developed in order to maximise the number of independent pieces of information contained in the measurements.

With the aim of quantifying the two independent pieces of information, an eigenvector expansion of the $\mathbf{A}$ matrix can be performed as for the characterization of ozone profiles retrieved from solar infrared absorption spectra (Barret et al., 2002; see also Rodgers, 1990, 2000). From this eigenvector expansion of the A matrix and Eq. (3), the following expression is derived:

$\widehat{z}=\Lambda z+(\mathbf{I}-\Lambda) z_{a}$,

where $\Lambda$ is the diagonal matrix with the eigenvalues of $\mathbf{A}$ on its diagonal, and $\widehat{z}, z$ and $z_{a}$ are the projections of the state vectors $\widehat{\boldsymbol{x}}, \boldsymbol{x}$, and $\boldsymbol{x}_{\boldsymbol{a}}$ on the right eigenvectors of $\mathbf{A}$ $\left(\widehat{z}=\mathbf{R}^{-1} \widehat{x} ; z=\mathbf{R}^{-1} \boldsymbol{x}\right.$, and $z_{a}=\mathbf{R}^{-1} \boldsymbol{x}_{\boldsymbol{a}}$, where $\mathbf{R}$ is the matrix of the right eigenvectors of $\mathbf{A})$. The $\Lambda$ matrix being diagonal, Eq. (9) shows that we can decompose the state vector into patterns. Those for which the corresponding eigenvalues are close to 1 will be well reproduced by the measurement system, while those for which the corresponding eigenvalues are close to 0 will come mainly from the a priori state. Such an eigenvectors expansion has been applied to the typical $\mathrm{NO}_{2}$ GB UV-visible averaging kernels matrix shown in Fig. 2. The eigenvectors corresponding to the six largest eigenvalues are plotted in Fig. 5. The first eigenvalue is close to unity, implying a $100 \%$ contribution of the measurements in this pattern. This pattern also confirms that $13-37 \mathrm{~km}$ is the altitude range where significant information on the vertical distribution of $\mathrm{NO}_{2}$ is present in the measurements. The next two patterns correspond to eigenvalues of 0.63 and 0.27 , which means that both the measurements and the a priori contribute. For the last three patterns having eigenvalues close to 0 , only the a priori state contributes.

\section{Retrieval results - correlative comparisons}

Our retrieval algorithm has been validated in the present study through comparison of the retrieved profiles with correlative data from the balloon-borne SAOZ and DOAS instruments and the POAM III and HALOE satellite instruments. These balloon and satellite techniques have been chosen because they cover complementary altitude ranges $(\sim$ $15-30 \mathrm{~km}$ for balloons and $\sim 20-45 \mathrm{~km}$ for satellites) and they all offer a good vertical resolution of about $1-2 \mathrm{~km}$. Satellites also offer the advantage to operate year-round, allowing a larger number of coincident events with the GB observations than the balloons.

The significant difference in vertical resolution between the GB and correlative profiles brings the concept of smoothing error into the comparison method. The $\mathrm{NO}_{2}$ density provided by a high-resolution correlative instrument contains information confined to only a few $\mathrm{km}$ around the retrieval altitude. For the same retrieval altitude, the information coming from a GB measurement spreads over a much larger altitude range. This drastic difference in perception of the true $\mathrm{NO}_{2}$ profile affects direct comparisons with large smoothing errors. One way to reduce these errors is to degrade the highresolution of the satellite and balloon profiles to the lower resolution of GB profiles using the following adaptation of Eq. (3) (Connor et al., 1994):

$x_{s}=x_{a}+\mathbf{A}\left(x_{c}-x_{a}\right)$,

where $\mathbf{A}$ is the GB UV-visible averaging kernels matrix, $\boldsymbol{x}_{\boldsymbol{a}}$ is the a priori profile used in the retrieval, $\boldsymbol{x}_{\boldsymbol{c}}$ is the correlative profile, and $\boldsymbol{x}_{\boldsymbol{s}}$ is the smoothed or convolved profile, which is what the retrieval should produce assuming that $\boldsymbol{x}_{\boldsymbol{c}}$ is the true profile and that the only source of error is the smoothing error 

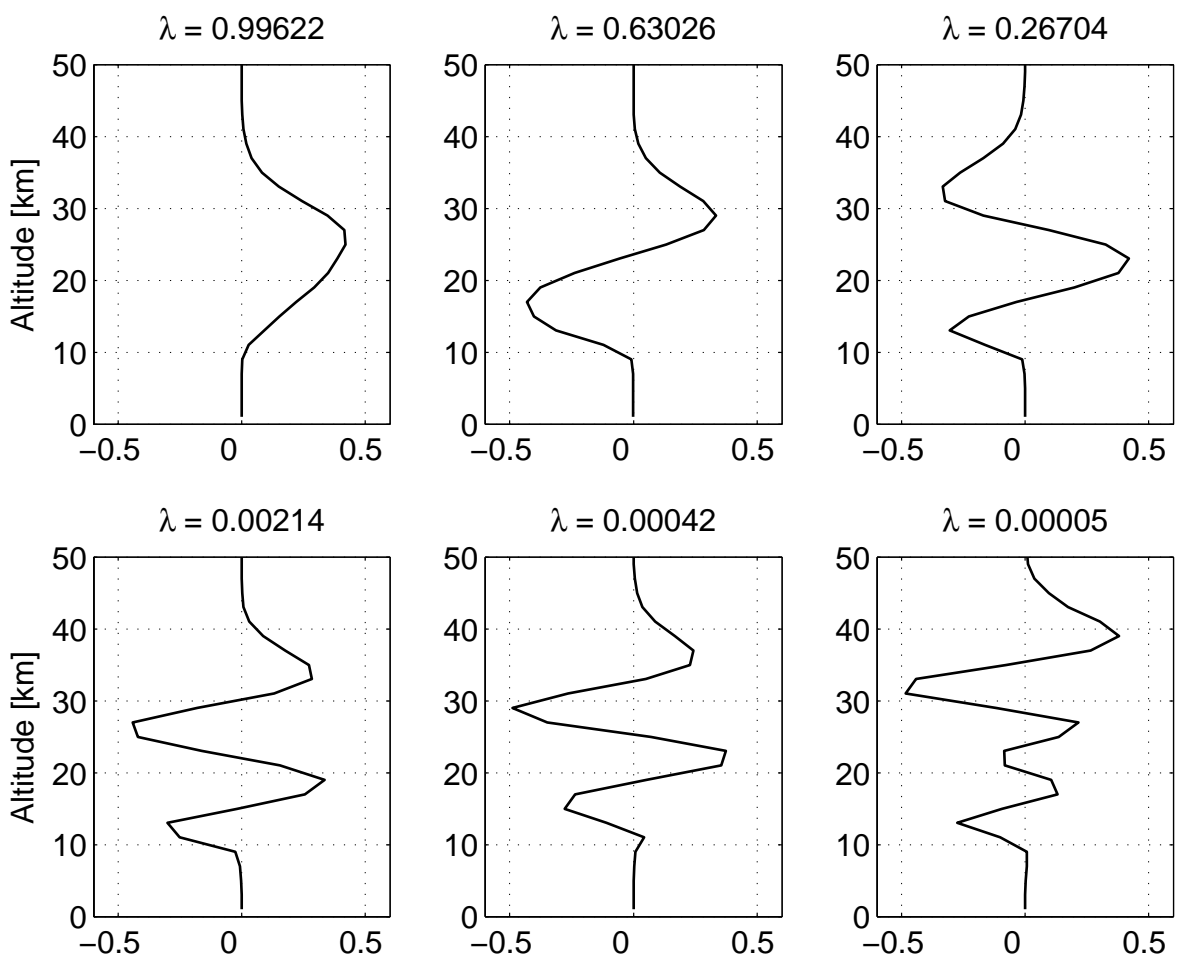

Fig. 5. Typical leading eigenvectors of the A matrix and their corresponding eigenvalues. They are calculated for the sunset Harestua 25 May 2001 retrieval.

(see Eq. 3). The correlative profiles cover a limited altitude range (e.g., $\sim 13-29 \mathrm{~km}$ for the SAOZ balloon) but according to the smoothing method used (see Eq. 10), they have to be extended over the same altitude grid as the averaging kernels. In the present study, they have been completed below and above the covered altitude range by the a priori profile scaled by the ratios between the correlative and a priori profiles at the lower and upper altitude limits of the correlative profile, respectively; e.g. a SAOZ balloon profile is completed below $13 \mathrm{~km}$ by the a priori profile scaled by the ratio between the $\mathrm{SAOZ}$ balloon and a priori profiles at $13 \mathrm{~km}$, and above $29 \mathrm{~km}$ by the a priori profile scaled by the ratio of the SAOZ balloon and a priori profiles at $29 \mathrm{~km}$. This scaling avoids the presence of large discontinuities at the lower and upper limits of the original altitude range of the correlative profile.

Each retrieval has also been quality-checked by comparing the absolute slant column densities (SCDs) calculated using the retrieved profile and the measured ones. The SCDs calculated with the retrieved profile fit generally very well with the measurements as can be seen in Fig. 6. This plot also illustrates the difference between the SCDs calculated using the a priori and retrieved profiles.

\subsection{SAOZ balloon comparisons}

The SAOZ balloon gondola is a UV-visible spectrometer able to provide vertical profiles of $\mathrm{O}_{3}, \mathrm{NO}_{2}, \mathrm{OClO}, \mathrm{BrO}$ and $\mathrm{H}_{2} \mathrm{O}$

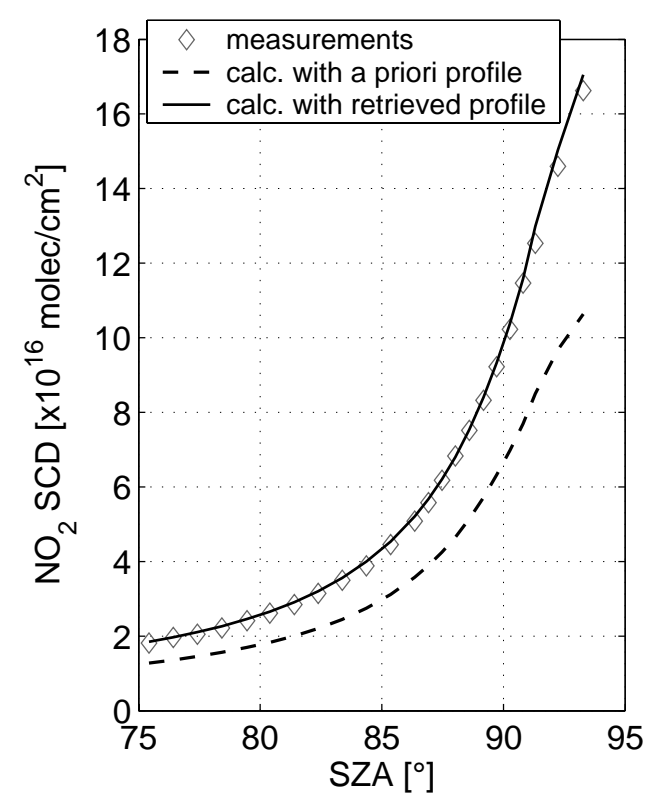

Fig. 6. Comparison between measurements and SCDs calculated using the a priori and retrieved profiles for the sunset Harestua 25 May 2001 retrieval. The error bars on the measurements are contained within the symbols (typical error values amount to $5 \times 10^{14}$ molecules $/ \mathrm{cm}^{2}$ and correspond to one standard deviation of the statistical error from the DOAS fitting). 

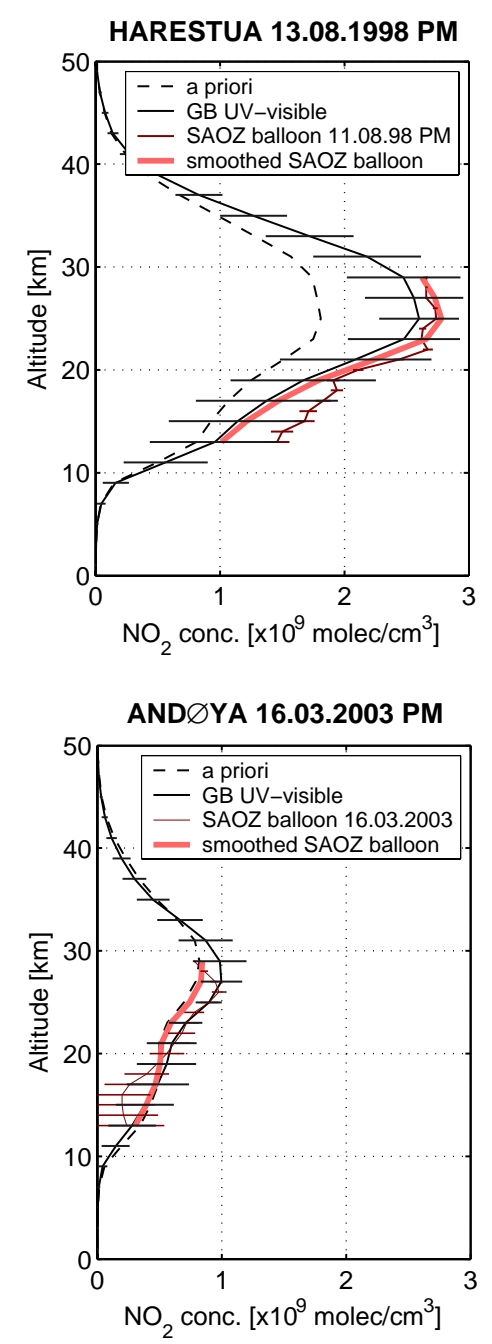

HARESTUA 28.08.1998 PM

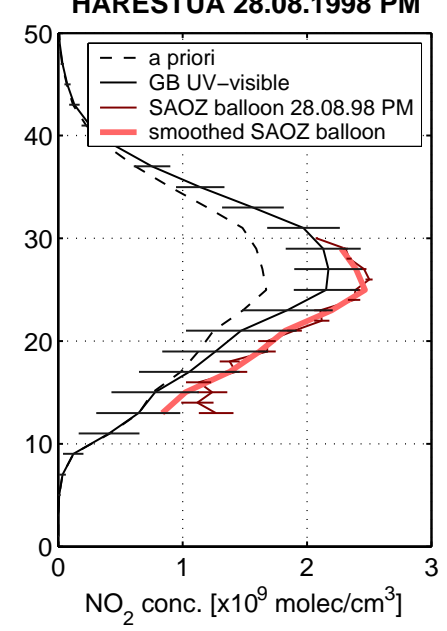

AND $\varnothing$ Y 27.03.2003 PM

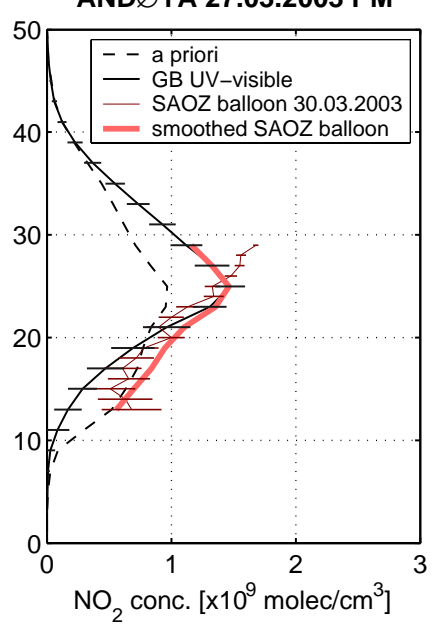

HARESTUA 24.08.2001 PM

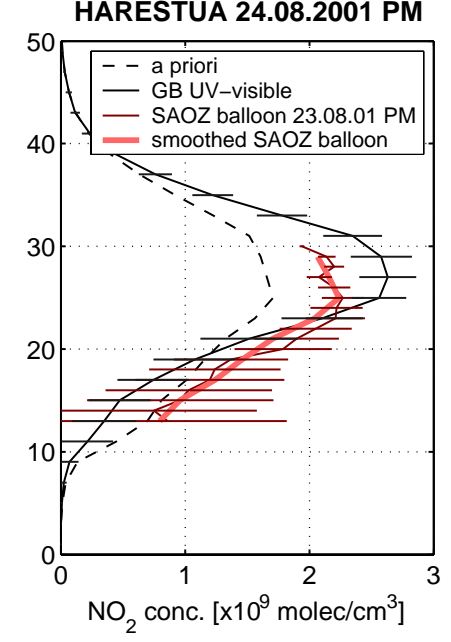

Relative differences

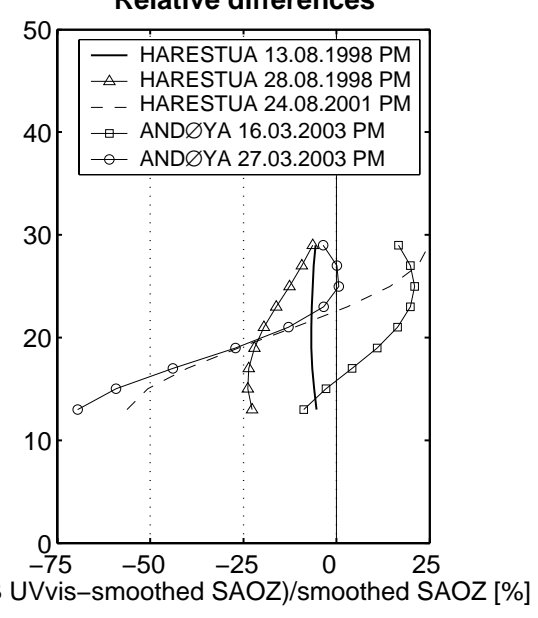

Fig. 7. Comparison between ground-based UV-visible profiles at Harestua (sunset, summer conditions) and Andøya (sunset, late winter-early spring conditions) and SAOZ balloon profiles. In the 5 cases, SAOZ balloons were launched from Kiruna. For direct comparison, SAOZ balloon profiles have been smoothed by convolving them with the ground-based UV-visible averaging kernels. The relative differences appear in the right lower plot.

during the ascent at sunset or descent at sunrise of the balloon and from float at $30 \mathrm{~km}$ (solar occultation). The balloon version of the SAOZ instrument is very similar to the one used for GB measurements (Pommereau and Goutail, 1988). $\mathrm{NO}_{2}$ is measured in the spectral region from 410 to $530 \mathrm{~nm}$ using the cross sections measured at $220 \mathrm{~K}$ by Vandaele et al. (1998). All the flights used for the GB-SAOZ balloon comparisons originated in Kiruna $\left(68^{\circ} \mathrm{N}, 21^{\circ} \mathrm{E}\right)$ in Sweden and occurred at sunset. Since the $\mathrm{SAOZ}$ balloon $\mathrm{NO}_{2}$ data have not been corrected for photochemical variations along the line of sight, only the ascent data are taken into account for the comparisons. These are provided with a vertical resolution of $1 \mathrm{~km}$. Five coincident events were found between the GB and balloon observations: three in summer conditions (Harestua GB data) and two in early spring conditions (Andøya GB data). GB UV-visible data are not always avail- able for the days where SAOZ balloon flights occur. Therefore, several days can separate GB and balloon-borne observations. Due to the rather large latitude difference $\left(8^{\circ}\right)$ between Harestua and Kiruna, comparisons are only relevant in summer conditions where stable air masses are present most of the time above this latitude region $\left(60^{\circ} \mathrm{N}-70^{\circ} \mathrm{N}\right)$. This is in contrast with winter and early spring conditions where large dynamical effects occur, especially above Harestua that is often located close to the edge of the wintertime polar vortex. Most of the time air masses with different histories are therefore probed from both stations making the profile comparisons irrelevant.

The results of the comparisons with SAOZ balloon profiles are shown in Fig. 7. The agreement obtained between GB UV-visible and smoothed SAOZ balloon profiles is good for the Harestua 13 and 28 August and Andøya 16 March 
Table 1. 13-29 $\mathrm{km} \mathrm{NO}_{2}$ partial columns values calculated from coincident ground-based UV-visible and smoothed SAOZ balloon profiles at Harestua and Andøya at sunset. In the 5 cases, the SAOZ balloons were launched from Kiruna. The relative differences in $\%$ appear in the third row.

\begin{tabular}{lccccc}
\hline & \multicolumn{3}{c}{ Harestua } & \multicolumn{2}{c}{ Andøya } \\
\hline & 13 Aug. 1998 & 28 Aug. 1998 & 24 Aug. 2001 & 16 Mar. 2003 & 27 Mar. 2003 \\
\hline $\begin{array}{l}\text { (a) GB UV-visible } \\
\left(\times 10^{15} \text { molec/cm }{ }^{2}\right)\end{array}$ & 3.13 & 2.43 & 2.51 & 1.06 & 1.43 \\
$\begin{array}{l}(b) \text { Smoothed SAOZ balloon } \\
\left(\times 10^{15} \text { molec/cm }{ }^{2}\right)\end{array}$ & 3.34 & 2.89 & 2.65 & 0.93 & 1.72 \\
$(\mathrm{a}-\mathrm{b}) / \mathrm{b} \times 100(\%)$ & -6 & -16 & -5 & +14 & -17 \\
\hline
\end{tabular}

Table 2. $13-37 \mathrm{~km} \mathrm{NO}_{2}$ partial columns values calculated from coincident ground-based UV-visible and smoothed DOAS balloon profiles at Harestua at sunset. In both cases, the DOAS balloons were launched from Kiruna. The relative differences in $\%$ appear in the third row.

\begin{tabular}{lcc}
\hline & 19 Aug. 1998 & 19 Aug. 2001 \\
\hline (a) GB UV-visible $\left(\times 10^{15}\right.$ molec $\left./ \mathrm{cm}^{2}\right)$ & 4.01 & 4.24 \\
(b) smoothed DOAS balloon $\left(\times 10^{15} \mathrm{molec} / \mathrm{cm}^{2}\right)$ & 4.10 & 3.41 \\
$(\mathrm{a}-\mathrm{b}) / \mathrm{b} \times 100(\%)$ & -2 & +24 \\
\hline
\end{tabular}

cases, both profiles differing over the entire $13-29 \mathrm{~km}$ altitude range by less than $7 \%, 25 \%$, and $21 \%$, respectively. For both other coincident days, the relative difference is smaller than $25 \%$ above $20 \mathrm{~km}$ but larger discrepancies are observed below this altitude level (relative difference up to 70\%). For the Andøya 27 March case, dynamical effects could be argued to explain the observed discrepancies since it is the end of the NH vortex season and three days elapsed between the GB and balloon-borne observations. However, a check of the potential vorticity at $475 \mathrm{~K}$ has shown that both balloon and GB measurements were performed outside the polar vortex.

The $13-29 \mathrm{~km} \mathrm{NO}_{2}$ partial column values calculated by integrating the GB UV-visible and smoothed SAOZ balloon profiles are presented in Table 1. The comparison gives good agreement since partial column values differ by less than $17 \%$ for the 5 coincident events.

\subsection{DOAS balloon comparisons}

The DOAS balloon instrument is extensively described in Ferlemann et al. (2000). It consists of two thermostated $(273 \mathrm{~K})$ grating spectrometers in which the UV (316$418 \mathrm{~nm})$ and visible $(399.9-653 \mathrm{~nm})$ parts of the sunlight are analyzed separately. Light detection is performed with two cooled photodiode array detectors (1024 diodes, $263 \mathrm{~K}$ ). As it is designed, the instrument can provide atmospheric column abundances or profiles of $\mathrm{O}_{3}, \mathrm{NO}_{2}, \mathrm{NO}_{3}, \mathrm{IO}, \mathrm{OIO}$,
$\mathrm{OClO}, \mathrm{BrO}, \mathrm{O}_{4}, \mathrm{CH}_{2} \mathrm{O}$, and $\mathrm{H}_{2} \mathrm{O}$. Among the ten flights of the DOAS instrument successfully conducted until now, two - originating from Kiruna - are appropriate for comparison with the Harestua GB UV-visible data. These are 19 August 1998 and 21 August 2001 at sunset. For the same reason as for the SAOZ balloons, only ascent data are used here. Concerning the second flight, the only day around 21 August 2001 where GB UV-visible data are available at Harestua is 19 August 2001.

The results of the profiles comparison for both coincident days are shown in Fig. 8. A good agreement is observed between the GB profile inversion and the DOAS balloon for the 19 August 1998 case where the relative difference between both profiles is smaller than $4 \%$ over the whole altitude range. Concerning the 19 August 2001 comparison, the GB UV-visible profile is clearly above the smoothed DOAS balloon one in the $15-39 \mathrm{~km}$ altitude range, with a maximum overestimation of $30 \%$ near $27 \mathrm{~km}$.

The $13-37 \mathrm{~km} \mathrm{NO}_{2}$ partial column values calculated from the GB UV-visible and smoothed DOAS balloon profiles are presented in Table 2. A reasonably good agreement is observed since GB profile inversion and balloon differ by $-2 \%$ and $+24 \%$ in the 19 August 1998 and 2001 cases, respectively. 

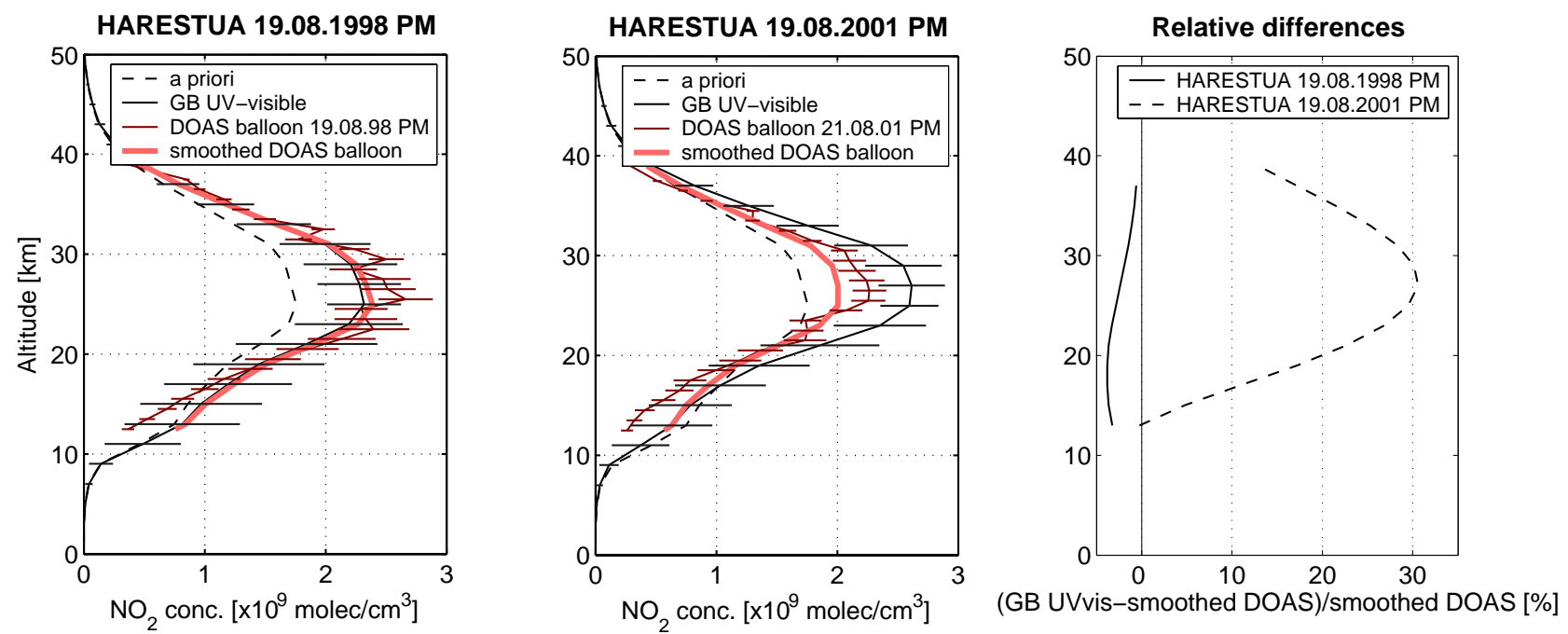

Fig. 8. Comparison between ground-based UV-visible profiles at Harestua and DOAS balloon profiles for two sunsets in summer conditions. DOAS balloons were launched from Kiruna. For direct comparison, DOAS balloon profiles have been smoothed by convolving them with the ground-based UV-visible averaging kernels. The relative differences appear in the right plot.

\subsection{POAM III comparisons}

POAM III is a nine-channel $(0.354-1.018 \mu \mathrm{m})$ solar occultation instrument launched onboard the Satellite Pour l'Observation de la Terre (SPOT) 4 in March 1998 (Randall et al., 2002). It has been designed to measure stratospheric profiles of $\mathrm{O}_{3}, \mathrm{NO}_{2}$ and water vapor densities, as well as aerosol extinction and temperature. $\mathrm{NO}_{2}$ densities are retrieved from 20 to $45 \mathrm{~km}$ through differential measurements at $439.6 \mathrm{~nm}\left(\mathrm{NO}_{2}\right.$-"on" channel) and $442.2 \mathrm{~nm}\left(\mathrm{NO}_{2}\right.$-"off" channel). The vertical resolution is about $2 \mathrm{~km}$ at altitudes below $40 \mathrm{~km}$ and decreases to more than $7 \mathrm{~km}$ at an altitude of $45 \mathrm{~km}$. The POAM III retrievals do not include a correction for the diurnal variation of $\mathrm{NO}_{2}$ along a solar occultation measurement line of sight. The criterion used for spatial coincidence is location of the POAM III profiles at tangent point within $5^{\circ}$ latitude and $5^{\circ}$ longitude of Harestua. Concerning the temporal coincidence, days of POAM III and GB observations are the same. 76 coincident events were found during the period from mid-June 1998 to mid-September 2000, 39 and 37 sunsets in spring and summer conditions, respectively.

Examples of profile comparisons are shown in Fig. 9. A good agreement is obtained for 10 June 1998 and 5 June 1999 coincident events: the relative difference is smaller than $25 \%$ in the whole altitude range. For both cases, the largest relative difference values are observed below $25 \mathrm{~km}$ with GB UV-visible inversion smaller than POAM III. This underestimation of the POAM III data by the GB UV-visible retrievals at low altitude levels is larger in the third case (25 July 1999) with difference values up to $40 \%$. This behaviour is systematic since it clearly appears when profiles are averaged, as illustrated in Fig. 10. Averages for spring and summer conditions have been plotted separately because of the difference in the polar vortex conditions between both seasons at Harestua (possible presence and absence of the polar vortex in spring and summer, respectively). Figure 10 shows that the magnitude of the underestimation is similar in both spring and summer. Its possible origin is discussed later in Sect. 5.4 since it is also observed in the comparisons with HALOE profiles.

The $20-37 \mathrm{~km} \mathrm{NO} \mathrm{NO}_{2}$ partial columns are compared in Fig. 11. This altitude range has been chosen because it is the common range where GB UV-visible retrieval and POAM III give reliable information on the vertical distribution of the $\mathrm{NO}_{2}$ concentration. Except for two coincident days in 2000, the GB UV-visible columns underestimate the POAM III data by maximum $26 \%$. In their validation study of POAM III NO 2 measurements, Randall et al. (2002) have compared the $20-45 \mathrm{~km}$ POAM III NO 2 partial columns to total columns measured at Kiruna using a GB UV-visible spectrometer. They found that POAM III underestimates the GB total columns, mainly because an expected low bias is present in the POAM III data since they do not include the tropospheric, lower stratospheric, and upper stratospheric $\mathrm{NO}_{2}$ seen by the GB instruments. Such an underestimation (up to $30 \%$ ) by POAM III is also observed when the POAM III $20-37 \mathrm{~km} \mathrm{NO}_{2}$ partial columns are compared to the total columns calculated from our retrieved profiles, meaning that results consistent with those of Randall et al. (2002) can be obtained when we use their comparison method. These results are not shown here because we found that comparing GB total and POAM III partial columns is not the most appropriate method of comparison.

Fig. 11 also shows that the relative difference between the GB UV-visible and smoothed POAM III $20-37 \mathrm{~km} \mathrm{NO}_{2}$ 

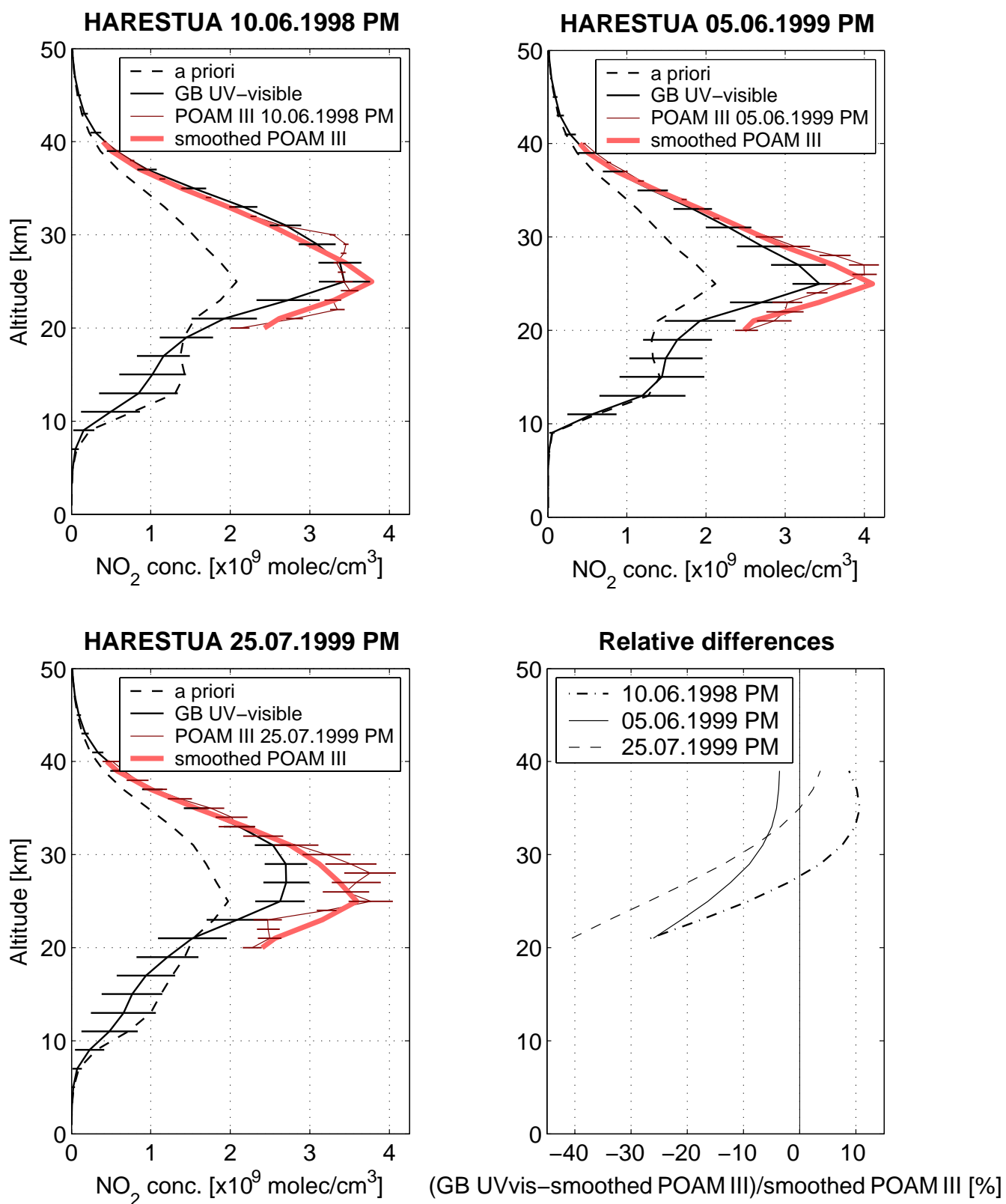

Fig. 9. Examples of comparison between ground-based UV-visible and POAM III profiles at Harestua (sunset conditions). For direct comparison, POAM III profiles have been smoothed by convolving them with the ground-based UV-visible averaging kernels. The relative differences appear in the right lower plot.

partial columns varies from year to year, especially between spring 1999 and spring 2000 where mean relative difference values of $-18 \%$ and $-8 \%$ are observed, respectively.

\subsection{HALOE comparisons}

HALOE was launched on board the Upper Atmosphere Research Satellite (UARS) in September 1991 (Gordley et al., 1996). As for POAM III, the satellite instrument probes the atmosphere in solar occultation. Vertical profiles of tempera- ture, $\mathrm{O}_{3}, \mathrm{HCl}, \mathrm{HF}, \mathrm{CH}_{4}, \mathrm{NO}, \mathrm{NO}_{2}$, and aerosol extinction are inferred from two infrared channels centered at $5.26 \mu \mathrm{m}$ and $6.25 \mu \mathrm{m}$. The HALOE $\mathrm{NO}_{2}$ measurements extend from the lower stratosphere $(\sim 10 \mathrm{~km})$ to $50 \mathrm{~km}$ of altitude. However, large error bars are sometimes observed below $25 \mathrm{~km}$, the error bars becoming larger as the altitude decreases. Due to this reduction of reliability in the lower stratosphere, only HALOE data corresponding to altitude levels higher than $20 \mathrm{~km}$ have been used for the comparison. In this altitude range $(20-50 \mathrm{~km})$, the vertical resolution of the HALOE 


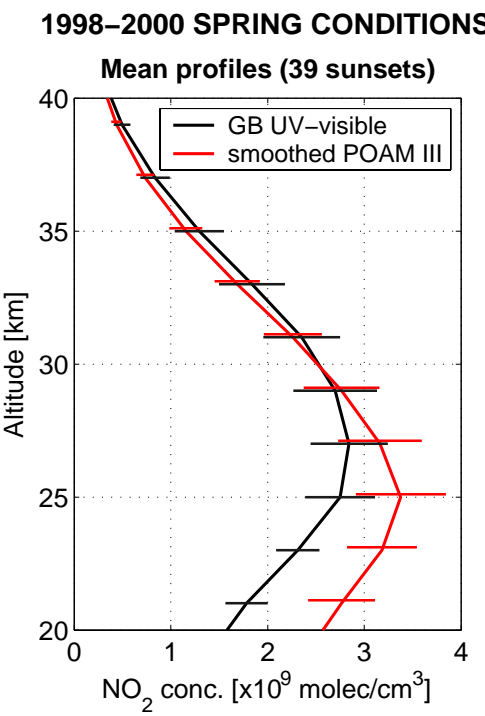

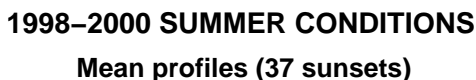
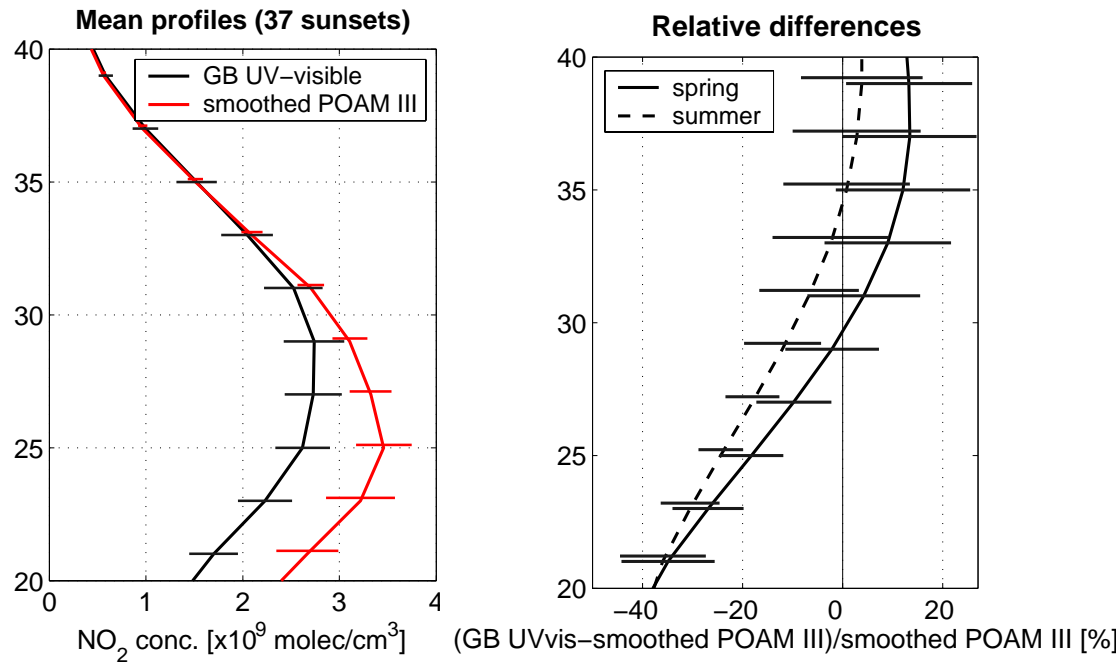

Fig. 10. Comparison of averaged ground-based UV-visible and smoothed POAM III profiles for sunset spring (left plot) and sunset summer (middle plot) conditions at Harestua for the period from mid-June 1998 to mid-September 2000. The relative differences appear in the right plot. The error bars represent the standard deviations of the GB, POAM III, and relative difference profiles. They are offset high by $0.2 \mathrm{~km}$ on the smoothed POAM III and summer relative difference profiles for clarity.
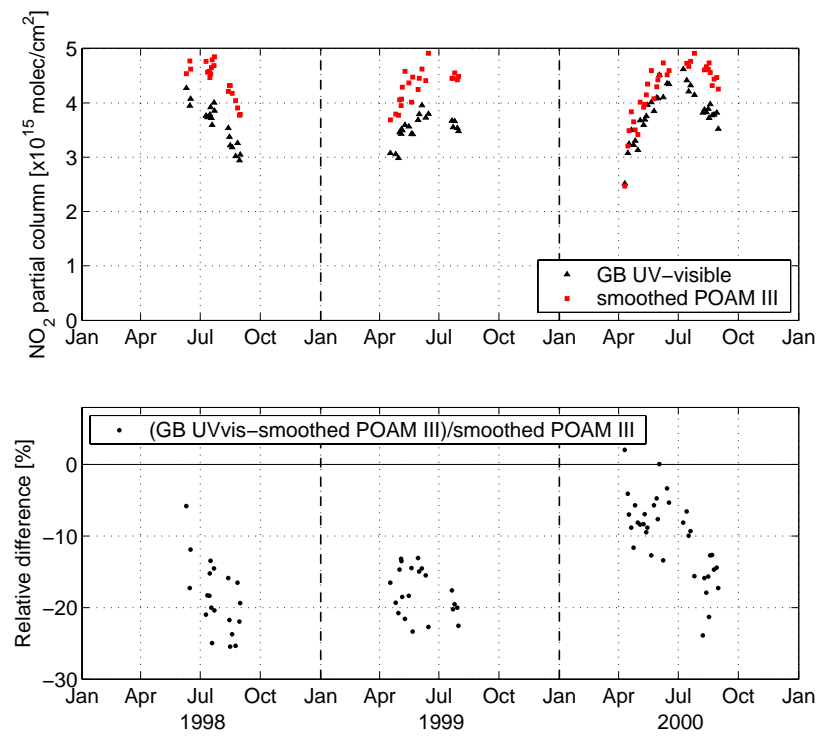

Fig. 11. Comparison of the sunset $20-37 \mathrm{~km} \mathrm{NO} 2$ partial columns calculated from the coincident ground-based UV-visible and smoothed POAM III profiles at Harestua for the period 19982000. The relative differences appear in the lower plot.

observations of $\mathrm{NO}_{2}$ is $2 \mathrm{~km}$. In contrast to POAM III, the HALOE processing algorithm includes a basic correction for the line of sight gradients of $\mathrm{NO}_{2}$ concentration across the limb due to the marked diurnal variation of this species. As for POAM III comparisons, the criterion used for spatial coincidence is location of the HALOE profiles at tangent point within $5^{\circ}$ latitude and $5^{\circ}$ longitude of Harestua. Concerning the temporal coincidence, days of HALOE and GB observations are the same. Using these criteria, 22 coincident events (3 at sunrise and 19 at sunset) were found for late winterspring conditions and 8 ( 6 at sunrise and 2 at sunset) for the summer-early fall period.

Figure 12 shows the comparison in the $20-40 \mathrm{~km}$ altitude range between the GB UV-visible and smoothed HALOE $\mathrm{NO}_{2}$ profiles averaged for late winter-early spring and summer-early fall conditions, sunrise and sunset being treated separately. Comparison results above $40 \mathrm{~km}$ are not shown since there is no information any more on the vertical distribution of $\mathrm{NO}_{2}$ above $\sim 37 \mathrm{~km}$ in the GB measurements and it is therefore essentially a comparison with the a priori profile. Both GB profile inversion and HALOE agree well above $\sim 28 \mathrm{~km}$. Below this altitude, a systematic underestimation of the HALOE data by the GB profile inversion occurs as in the POAM III comparisons, although the observed differences are here within the variability of both profiles (except in late winter-spring at sunrise but the statistics significance is poor in these conditions). The comparison of Fig. 10 and 12 also shows that the agreement with HALOE at sunset is significantly better than with POAM III for both spring and summer conditions (relatives differences below $25 \mathrm{~km}$ smaller than $20 \%$ instead of being comprised between $20 \%$ and $40 \%$ for POAM III). A problem in the GB profile retrievals cannot be the main cause of the systematic underestimation of the satellite data by the GB retrievals since a good agreement has been observed with the SAOZ and DOAS balloons in the $20-25 \mathrm{~km}$ range, balloon data being the most suitable correlative observations available 
LATE WINTER-SPRING CONDITIONS
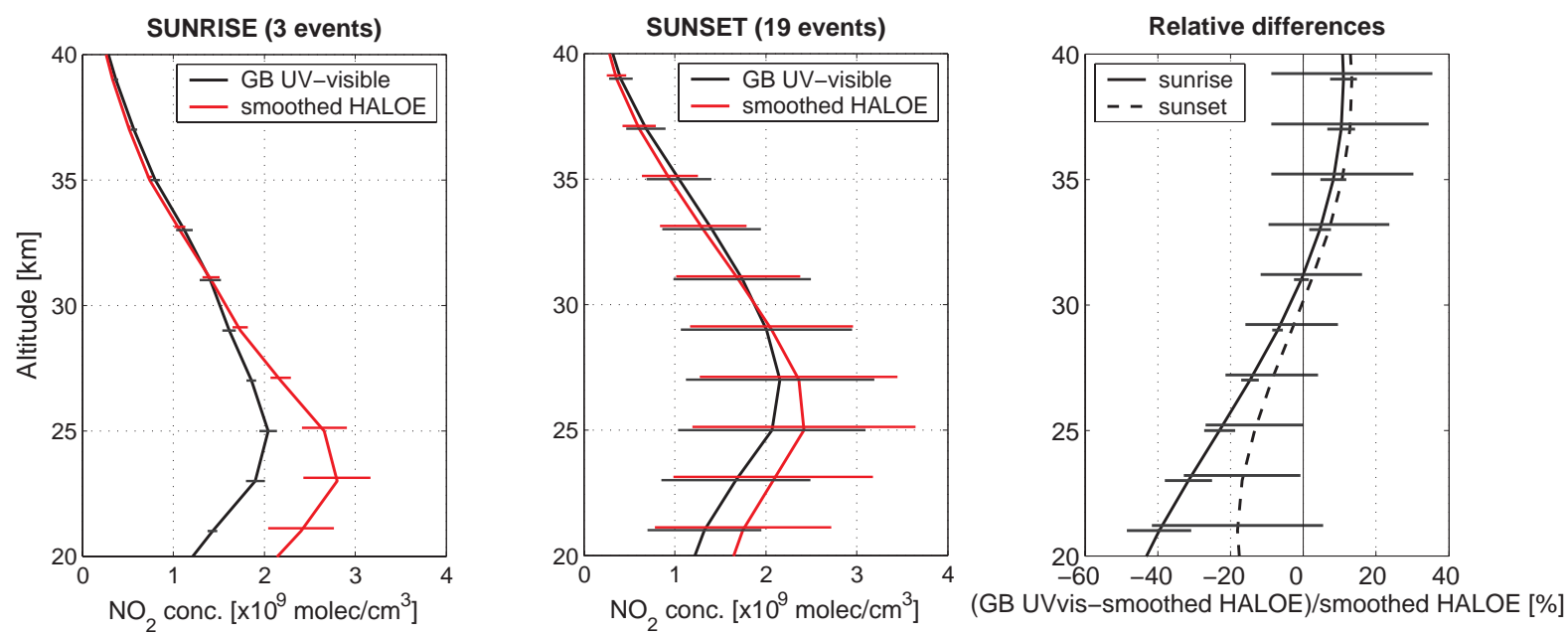

SUMMER-EARLY FALL CONDITIONS
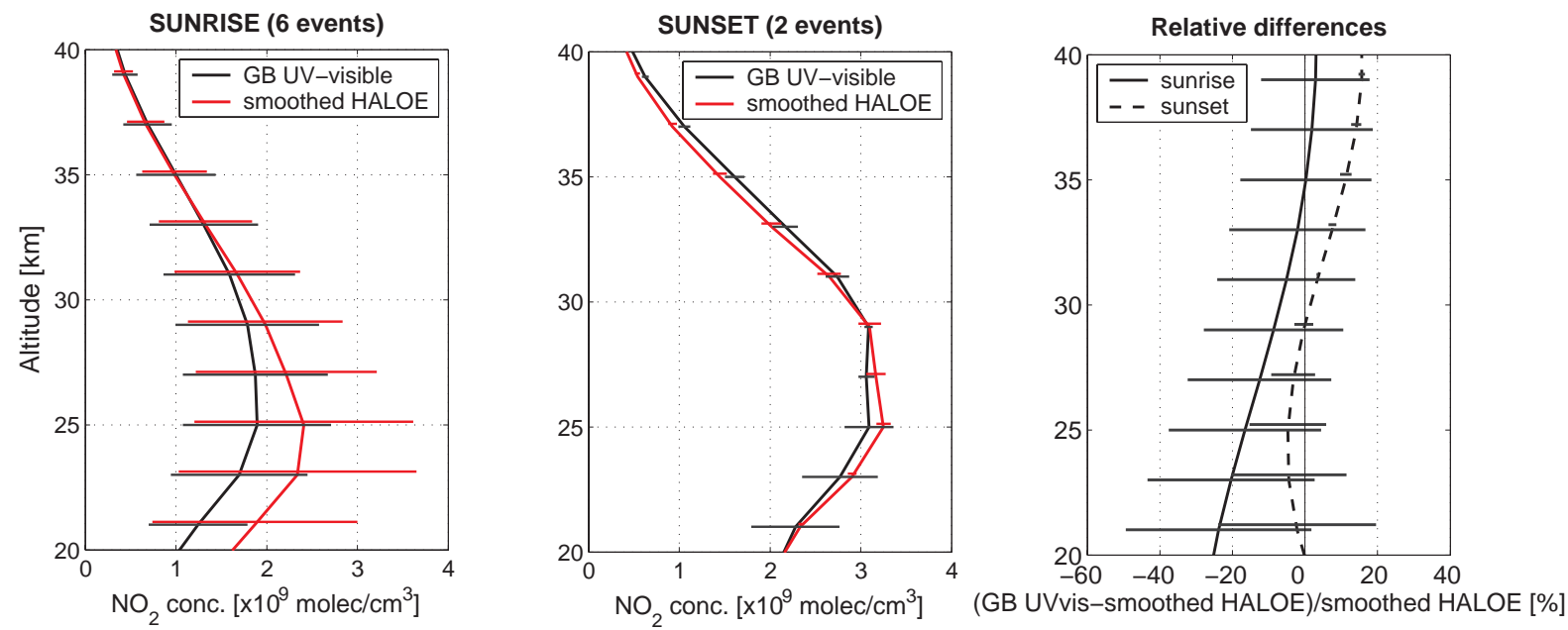

Fig. 12. Comparison of coincident ground-based UV-visible and smoothed HALOE profiles separately averaged for sunrise and sunset for late winter-spring (upper plots) and summer-early fall (lower plots) conditions at Harestua. The coincident events cover the period from mid-June 1998 to mid-September 2001. The relative differences appear in the right plots. The error bars represent the standard deviations of the GB, HALOE, and relative difference profiles. They are offset high by $0.2 \mathrm{~km}$ on the smoothed HALOE and sunset relative difference profiles for clarity.

to validate our retrievals in this altitude range. Therefore, this feature would be more likely due to a limitation of the HALOE and POAM III instruments for measuring $\mathrm{NO}_{2}$ at these low altitude levels. The possible error sources on the HALOE and POAM III data are described in detail in Gordley et al. (1996) and Randall et al. (2002). A source of systematic error is the strong variations of $\mathrm{NO}_{2}$ along a solar occultation measurement line of sight. Neglecting a correction for the line of sight variations can result in a systematic overestimation in $\mathrm{NO}_{2}$ below $25 \mathrm{~km}$. According to Randall et al. (2002) and Newchurch et al. (1996), this overestimation is $\sim 20 \%$ at $20 \mathrm{~km}$ whereas Roscoe and Pyle (1987) estimate it to maximum $1 \%$ for the conditions of the present comparisons. The uncertainty on the diurnal effect correction is therefore very large, mainly because this correction strongly depends on the photochemical model (including the initialization settings) used for calculating it. Nevertheless, the absence of such a correction in the POAM III retrievals could at least partly explain the large discrepancies systematically observed between the GB profile retrievals and POAM III below $25 \mathrm{~km}$ since this explanation is consistent with the significantly better agreement observed with HALOE - which includes a correction for the diurnal effect - than with POAM III in sunset spring and summer conditions. The comparison of the relative differences in these conditions (below 20\% for HALOE and comprised between $20 \%$ and $40 \%$ for POAM III) suggests that the magnitude of the diurnal effect correction could reach at least $10 \%$. This effect could also play 

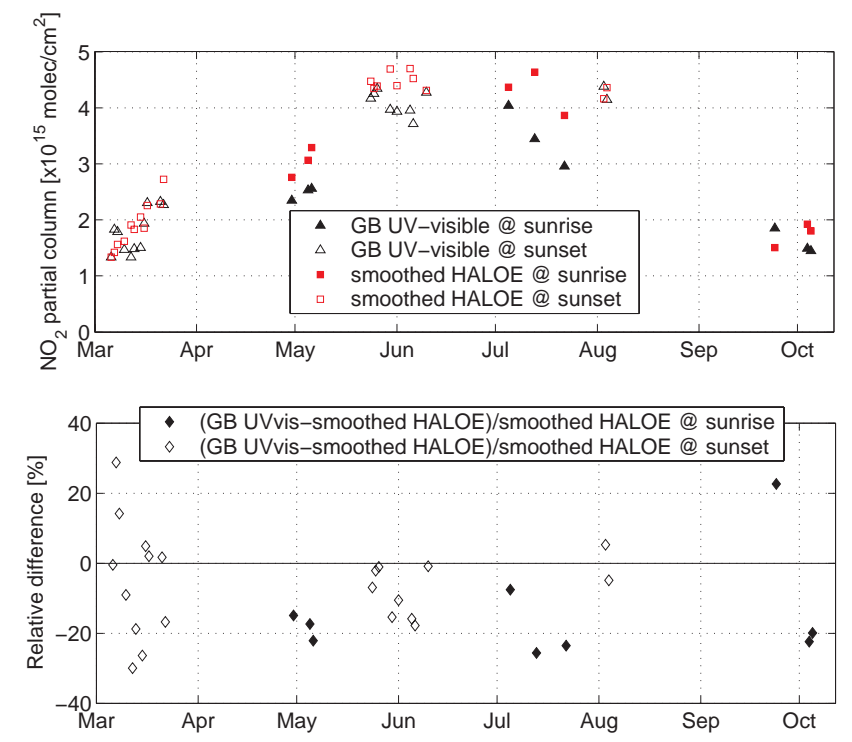

Fig. 13. Comparison of the $20-37 \mathrm{~km} \mathrm{NO}_{2}$ partial columns calculated from the coincident ground-based UV-visible and smoothed HALOE profiles at Harestua. Due to the small number of coincident events, the sunrise and sunset partial columns for the 1998-2001 period have been gathered in the same plot. The relative differences appear in the lower plot.

a significant role in the difference observed between sunrise and sunset in the agreement between GB retrievals and HALOE data (larger discrepancies at sunrise than at sunset) since the uncertainty on it can be 2 to 3 times larger at sunrise than at sunset (Gordley et al., 1996). More investigations - which are beyond the scope of the present study - are required to go one step further in the determination of the exact impact of this error source as well as others (e.g. the errors due to interfering absorbers and uncertainties on spectral parameters) on the agreement between GB retrievals and satellite instruments.

The $20-37 \mathrm{~km}$ GB UV-visible and HALOE $\mathrm{NO}_{2}$ partial columns are compared in Fig. 13. As for the comparison with POAM III, the 20-37 km altitude range has been chosen because it is the common range where data from GB UV-visible retrieval and HALOE are reliable. Due to the small number of coincident events, the sunrise and sunset partial columns for the 1998-2001 period have been gathered in the same plot and not plotted separately for sunrise and sunset and for each year as in the comparison with POAM III. Except for 7 coincident events ( 1 at sunrise and 6 at sunset) over a total number of 30, the GB retrievals underestimate the HALOE data. At sunset, the absolute value of the relative difference between the GB and smoothed HALOE partial columns is most of the time (18 coincident events over a total number of 21 ) smaller than $20 \%$, a maximum value of $28 \%$ being reached in March. During this late winter-early spring period where large dynamical effects occur above Harestua and the $\mathrm{NO}_{2}$ concentration is low, a large scatter is also observed in the relative differences between the GB UV-visible and HALOE data. At sunrise, the absolute value of the relative difference is comprised between $20 \%$ and $28 \%$ and is below $20 \%$ for 5 and 4 coincident events, respectively. In the HALOE $\mathrm{NO}_{2}$ validation study of Gordley et al. (1996), the HALOE column amounts above the $80 \mathrm{mb}$ pressure level $(\sim 17 \mathrm{~km})$ have been compared to the total column amounts measured by a GB spectrometer at Fritz Peak, Colorado $\left(40^{\circ} \mathrm{N}, 106^{\circ} \mathrm{W}\right)$. Days with significant tropospheric contribution have been excluded from the comparison. The HALOE observations were found to be lower than the GB ones by $10-30 \%$, mainly due to the fact that the HALOE column amounts above 80 $\mathrm{mb}$ do not include the lower stratospheric $\mathrm{NO}_{2}$ seen by the GB instrument. We have observed similar differences (15$40 \%$ ) when the HALOE $20-37 \mathrm{~km}$ partial columns are compared to the $\mathrm{NO}_{2}$ total columns calculated from our retrieved GB UV-visible profiles. Using the same method of comparing columns, results consistent with those of Gordley et al. (1996) can therefore be obtained. As for POAM III, these results are not shown here because the comparison method of Gordley et al. (1996) is not the most appropriate due the difference in the altitude ranges where the GB and HALOE columns are calculated.

\section{Conclusions}

$\mathrm{NO}_{2}$ stratospheric profiles have been retrieved from GB zenith-sky UV-visible observations using the OEM. The retrieval algorithm has been applied to observational data sets from the NDSC stations of Harestua and Andøya in Norway. The characterization of the retrievals has been performed as in the study of Barret et al. (2002) on the retrieval of ozone profiles from solar infrared absorption spectra. We have shown that about 2 independent pieces of information are contained in the measurements. Both components have been quantified from an eigenvector expansion of the averaging kernels matrix $\mathbf{A}$. We have also determined the impact on the number of independent pieces of information of the SZA sampling of the measurements and the extra-diagonal terms of the a priori covariance matrix. Concerning the error analysis, the profiles of the smoothing, measurement, and forward model parameter errors have been compared to the $\mathrm{NO}_{2}$ natural variability. The smoothing error clearly appears to be the main source of error. The total retrieval error is also well below the $\mathrm{NO}_{2}$ natural variability, pointing out that variations of the $\mathrm{NO}_{2}$ profile smaller than the natural variability can be detected from our GB UV-visible observations.

Retrieved $\mathrm{NO}_{2}$ stratospheric profiles and partial columns have been validated through comparisons with correlative balloon and satellite observations. Although the number of coincident events was too small to constitute a statistically significant comparison, a good agreement was generally found with SAOZ and DOAS balloons, especially in the 20-30 km altitude range. Concerning the partial columns 
between 13 and $29 \mathrm{~km}$ and 13 and $37 \mathrm{~km}$ for SAOZ and DOAS balloons, respectively, the relative difference reached a maximum value of $24 \%$. The correlative comparisons with the POAM III and HALOE satellite data showed a poorer agreement with our retrievals than those with the balloon data. When mean profiles were compared, the GB UVvisible retrievals systematically underestimated the satellite instruments below $25-27 \mathrm{~km}$ where the relative differences were generally comprised between $20 \%$ and $40 \%$. Since (1) this feature was observed for POAM III and HALOE data, and (2) a good agreement was found in the $20-30 \mathrm{~km}$ range with balloon measurements, it could be more likely due to a common limitation of both satellite solar occultation instruments at these low altitude levels. The impact on this systematic underestimation of a correction for the $\mathrm{NO}_{2}$ photochemical variation along a solar occultation measurement line of sight has been discussed. The comparison of partial columns between 20 and $37 \mathrm{~km}$ showed a better agreement with relative difference values smaller than $26 \%$ and $28 \%$ for POAM III and HALOE, respectively. We have also verified that using the same way of comparing columns, i.e. comparing the POAM III and HALOE partial columns to the GB total columns, results consistent with the POAM III and HALOE validation studies of Randall et al. (2002) and Gordley et al. (1996) can be obtained.

The results of the present work - especially those concerning the characterization of the retrievals and the extensive comparison exercise with correlative data - strengthen our confidence in the reliability and the robustness of the retrieval of the vertical distribution of stratospheric trace gas species from GB zenith-sky UV-visible observations. This technique offers new perspectives in the use of GB UVvisible networks such as the NDSC for the purpose of validation of satellite and balloon experiments as well as modelling data. Moreover, its application to combined observations in zenith, direct-sun, and off-axis (pointing towards the horizon) geometries - made possible due to recent instrumental developments in DOAS spectroscopy (Hönninger et al., 2004; Heckel et al., 2004) - will allow to retrieve information on the vertical distribution in both the stratosphere and troposphere, which is particularly important for species like $\mathrm{BrO}$ and $\mathrm{NO}_{2}$.

Acknowledgements. This research was financially supported by the Belgian Federal Science Policy Office (contracts ESAC II EV/35/3A and MO/35/006 \& 012) and the European Commission (contract QUILT, EVK2-2000-00545). M. P. Chipperfield (University of Leeds) is greatly acknowledged for providing us with the SLIMCAT data. We wish also to thank the POAM III and HALOE Science and Processing Teams. Finally, we are thankful to C. Fayt (IASB-BIRA) for her contribution to the observations at the Harestua and Andøya stations, and to L. Denis, H. K. Roscoe (BAS), and R. Schofield (NIWA) for fruitful discussions.

Edited by: J. Burrows

\section{References}

Barret, B., De Mazière, M., and Demoulin, P.: Retrieval and characterisation of ozone profiles from solar infrared spectra at the Jungfraujoch, J. Geophys. Res., 107 (D24), 4788, doi:10.1029/2001JD001298, 2002.

Brewer, A. W., McElroy, C. T., and Kerr, J. B.: Nitrogen dioxide concentration in the atmosphere, Nature, 246, 129-133, 1973.

Chipperfield, M. P.: Multiannual simulations with a threedimensional chemical transport model, J. Geophys. Res., 104 (D1), 1781-1805, 1999.

Connor, B. J., Siskind, D. E., Tsou, J. J., Parrish, A., and Remsberg, E. E.: Ground-based microwave observations of ozone in the upper stratosphere and mesosphere, J. Geophys. Res., 99 (D8), 16757-16770, 1994.

Errera, Q. and Fonteyn, D.: Four-dimensional variational chemical assimilation of CRISTA stratospheric measurements, J. Geophys. Res., 106 (D11), 12 253-12 265, 2001.

Ferlemann, F., Bauer, N., Fitzenberger, R., Harder, H., Osterkamp, H., Perner, D., Platt, U., Schneider, M., Vradelis, P., and Pfeilsticker, K.: Differential Optical Absorption Spectroscopy Instrument for stratospheric balloon-borne trace gas studies, Applied Optics, 39, 2377-2386, 2000.

Gordley, L. L., Russel III, J. M., Mickley, L. J., et al.: Validation of nitric oxide and nitrogen dioxide measurements made by the Halogen Occultation Experiment for UARS platform, J. Geophys. Res., 101 (D6), 10 241-10266, 1996.

Hendrick, F., Mueller, R., Sinnhuber, B.-M., et al.: Simulation of BrO Diurnal Variation and BrO Slant Columns: Intercomparison Exercise Between Three Model Packages, Proceedings of the 5th European Workshop on Stratospheric Ozone, Saint Jean de Luz, France, 27 Sept.-1 Oct. 1999, Air Pollution Research Report n 73, European Commission - DG XII, Brussels, 2000.

Hendrick, F., Van Roozendael, M., Kylling, A., Wittrock, F., von Friedeburg, C., Sanghavi, S., Petritoli, A., Denis, L., and Schofield, R.: Report on the workshop on radiative transfer modeling held at IASB-BIRA, Brussels, Belgium, on 3-4 October 2002, WP 2500 of the QUILT project (European commission, EVK2-CT2000-00059), http://nadir.nilu.no/quilt, 2003.

Heckel, A., Richter, A., Tarsu, T., Wittrock, F., Hak, C., Pundt, I., Junkermann, W., and Burrows, J. P.: MAX-DOAS measurements of formaldehyde in the Po-Valley, Atmos. Chem. Phys. Discuss., 4, 1151-1180, 2004,

SRef-ID: 1680-7375/acpd/2004-4-1151.

Heskes, H. J. and Boersma, K. F.: Averaging kernels for DOAS total-column satellite retrievals, Atmos. Chem. Phys., 3, 12851291, 2003,

SRef-ID: 1680-7324/acp/2003-3-1285.

Hönninger, G., von Friedeburg, C., and Platt, U.: Multi axis differential optical absorption spectroscopy (MAX-DOAS), Atmos. Chem. Phys., 4, 231-254, 2004,

SRef-ID: 1680-7324/acp/2004-4-231.

Huang, T., Walters, S., Brasseur, G., et al.: Description of SOCRATES - A Chemical Dynamical Radiative TwoDimensional Model, NCAR technical note no. TN-440+EDD, National Center for Atmospheric Research, Boulder, Colorado, 1998.

Kylling, A. and Mayer, B.: LibRadTran: A package for UV and visible radiative transfer calculations in the Earth's atmosphere, http://www.libradtran.org, 2003. 
Lee, A. M., Roscoe, H. K., Oldham, D. J., Squires, J. A. C., Sarkissian, A., and Pommereau, J.-P.: Improvements to the accuracy of zenith-sky measurements of $\mathrm{NO}_{2}$ by visible spectrometers, J. Quant. Spectr. Rad. Transfer, 52, 649-657, 1994.

McKenzie, R., Johnston, P. V., McElroy, C. T., Kerr, J. B., and Solomon, S.: Altitude distributions of stratospheric constituents from ground-based measurements at twilight, J. Geophys. Res., 96 (D8), 15 499-15 511, 1991.

Newchurch, M. J., Allen, M., Gunson, M. R., et al.: Stratospheric $\mathrm{NO}$ and $\mathrm{NO}_{2}$ abundances from ATMOS solar-occultation measurements, Geophys. Res. Lett., 23, 2373-2376, 1996.

Noxon, J. F.: Nitrogen dioxide in the stratosphere and troposphere measured by ground-based absorption spectroscopy, Science, 189, 547-549, 1975.

Platt, U.: Differential Optical Absorption Spectroscopy (DOAS), in: Air Monitoring By Spectroscopic Techniques, edited by: Sigrist, M. W., John Wiley and Sons, Inc., New York, 1994.

Pommereau, J. P. and Goutail, F.: $\mathrm{O}_{3}$ and $\mathrm{NO}_{2}$ ground-based measurements by visible spectrometry during Arctic winter and spring 1988, Geophys. Res. Lett., 15, 891-894, 1988.

Preston, K. E., Jones, R. L., and Roscoe, H. K.: Retrieval of $\mathrm{NO}_{2}$ vertical profiles from ground-based UV-visible measurements: Method and validation, J. Geophys. Res., 102 (D15), 19089 $19097,1997$.

Randall, C. E., Lumpe, J. D., Bevilacqua, R. M., et al.: Validation of POAM III NO 2 measurements, J. Geophys. Res., 107 (D20), 4432, doi:10.1029/2001JD001520, 2002.

Rodgers, C. D.: Retrieval of atmospheric temperature and composition from remote measurements of thermal radiation, Rev. Geophys. Space Phys., 14 (4), 609-624, 1976.
Rodgers, C. D.: Characterisation and error analysis of profiles retrieved from remote sounding measurements, J. Geophys. Res., 95 (D5), 5587-5595, 1990.

Rodgers, C. D.: Inverse Methods for Atmospheric Sounding, Theory and Practice, World Scientific Publishing, Singapore - NewJersey - London - Hong Kong, 2000.

Roscoe, H. K. and Pyle, J. A.: Measurements of solar occultation: the error in a naive retrieval if the constituent's concentration changes, J. Atmos. Chem., 5, 323-341, 1987.

Sander, S. P., Friedl, R. R., DeMore, W. B., et al.: Chemical Kinetics and Photochemical Data for Use in Stratospheric Modeling, Evaluation $n^{\circ} 13$, NASA JPL Publication 00-3, 2000.

Schofield, R., Connor, B. J., Kreher, K., Johnston, P. V., and Rodgers, C. D.: The retrieval of profile and chemical information from ground-based UV-visible spectroscopic measurements, J. Quant. Spectr. Rad. Transfer, 86, 115-131, 2004.

Sinnhuber, B.-M., Arlander, D. W., Bovensmann, H., et al.: Comparison of measurements and model calculations of stratospheric bromine monoxide, J. Geophys. Res., 107 (D19), 4398, doi:10.1029//2001JD000940, 2002.

Vandaele, A. C., Hermans, C., Simon, P. C., et al.: Measurements of the $\mathrm{NO}_{2}$ absorption cross-section from $42000 \mathrm{~cm}^{-1}$ to $10000 \mathrm{~cm}^{-1}(238-1000 \mathrm{~nm})$ at $220 \mathrm{~K}$ and $294 \mathrm{~K}$, J. Quant. Spectr. Rad. Transfer, 59, 171-184, 1998.

Van Roozendael, M., Fayt, C., Hermans, C., and Lambert, J.-C.: Ground-based UV-visible Measurements of $\mathrm{BrO}, \mathrm{NO}_{2}, \mathrm{O}_{3}$ and $\mathrm{OClO}$ at Harestua $\left(60^{\circ} \mathrm{N}\right)$ since 1994 , Proceedings of the 4 th European Workshop on Polar Stratospheric Ozone, Schliersee, Germany, 22-26 Sept. 1997, Air Pollution Research Report no. 66, European Commission - DG XII, Brussels, 1998. 